Article

\title{
An Integrated Multi-Criteria Approach for Planning Railway Passenger Transport in the Case of Uncertainty
}

\author{
Svetla Stoilova \\ Faculty of Transport, Technical University of Sofia, 8 Kl. Ohridski Blvd., 1000 Sofia, Bulgaria; \\ stoilova@tu-sofia.bg
}

Received: 11 May 2020; Accepted: 2 June 2020; Published: 4 June 2020

\begin{abstract}
The aim of this study is to elaborate on an integrated approach for transport planning in railway passenger transport in the case of uncertainty. The methodology consists of four stages. In the first stage, the parameters of a multi-criteria model in the case of uncertainty were determined. This includes defining the criteria for selection of a transport plan; formulation of the alternatives of the transport plan; formulation of the strategies and probability variants of passenger flow variation for each strategy. In the second stage, the weights of the probability variants of the strategies for change in passenger flow were determined using the analytic hierarchy process (AHP) method. The alternatives of the transport plan were ranked by applying the sequential interactive modeling for urban systems (SIMUS) method based on linear programming. The results for the values of the criterion of ranking obtained through the SIMUS method and the weights of the variants of passenger flow variation calculated with the AHP method were used as input in the expected values in the decision tree. The selection of a suitable alternative in the case of uncertainty was conducted in the third stage by applying the decision tree method. In the fourth stage, verification of the results was made using Laplace's criterion and Hurwitz's criterion. The integrated multi-criteria approach was applied for Bulgaria's railway network. The multi-criteria approach elaborated herein could be used for decision-making in the case of uncertainty about passenger flow; to investigate different strategies of passenger flow variation and to make decisions in case of instability of passenger flow or lack of sufficient travel data.
\end{abstract}

Keywords: SIMUS; AHP; decision tree; transport plan; Laplace's criterion; Hurwitz's criterion

\section{Introduction}

Successful transport planning depends on the possibilities of symmetry, on the one hand, between passenger satisfaction and the capabilities of the railway operators, and on the other hand, between the subjectivism of the decision maker and the importance of the criteria for assessment of the transport process. The elaboration of a new integrated approach to decision-making allows for the symmetry principles to be considered also in cases of uncertainty about passenger flow. Thus, a balance should be established between the probabilities for changes in passenger flow and the sustainability of the transport plan.

The number of trains, their categories, routes, and stops are the elements of the transport plan, which need to be determined. Passenger flow and transport demand have to be the subject of preliminary studies in order to establish the optimal organization of the transport process. Various criteria related to passenger transport service and the capabilities of railway operators influence transport planning. When passenger flow is pre-defined on the basis of statistics from sold tickets or counting of the passengers, the situation of decision-making concerning the transport plan is a 
situation of certainty. Passenger flow may change according to various factors, such as repairs to railway infrastructure; competitive modes of transport; change in the conditions of travel; increase of train operating speeds or other reasons. In such cases, the determination of an appropriate transport plan is carried out in a state of uncertainty. The uncertainty is a situation where there is not adequate data about the distribution of the demand or probabilities of different events. When the demand is not known but there is some information about the probabilities of the events, the situation of decision-making is under risk. The successful planning of passenger services requires a complex view not only when the demand for transport services has been established in advance, but also in cases where the size of passenger flow is uncertain. It is necessary to increase the effectiveness of the decision-making in case of risk and uncertainty, by studying the impact of variation in passenger flow and criteria related to the transport process.

The hypothesis of the study is that transport planning in railway passenger transport depends on technological and economic criteria; the uncertainty of passenger flow impacts the choice of a suitable alternative of the transport plan; the railway transport service could be improved by taking into account both the above criteria and the state of uncertainty.

The research questions that have to be solved to address the following issues: how to determine the probabilities of changes in passenger traffic to be used by the decision maker in transport planning; how the uncertainty in the change of the passenger flow affects the transport plan of passenger trains in the railway network; whether a stable solution can been established that is favorable for both passengers and the railway operator.

In the present study, the sequential interactive model for urban systems method (SIMUS), analytic hierarchy process method (AHP), the decision tree method, and the decision-making criteria-Laplace's criterion and Hurwitz' criterion-are proposed to assess railway passenger transport plan under uncertainty. The SIMUS method based on linear programming makes it possible to rank the alternatives of the transport plan according to multiple objectives, and does not use experts' assessment of the criteria. The decision tree allows for decision-making in the case of uncertainty on the basis of profits and probabilities for variation of passenger flow. The AHP method helps to determine the probabilities of variation of passenger flow.

The integration of the SIMUS method on the one hand and the AHP method on the other hand with the decision tree method allows for the development of an appropriate transport plan with given probabilities of change in passenger flow. The SIMUS method allows for decision-making in a state of certainty where different variants can be studied and compared at a predetermined known size of passenger flow. When the size of passenger flow is not known in advance, or the probabilities of its change are known, then decision-making is in a state of uncertainty and risk. The aim of the decision-maker is to be able to develop a transport plan in a state of uncertainty. The determination of the probabilities of changes in passenger flow can be done on the basis of expert assessments or by an analysis of statistical data about previous periods. Both approaches were used in this study, and on the basis of a study of the size of passenger traffic for a 10-year period, its tendency to decrease or increase compared to the previous year was established, and thus the strategies for changing the passenger flow were determined. The probabilities for the implementation of the strategies for change in passenger flow are determined by expert assessments. In the research, the AHP method is chosen, using expert assessment by an established scale. In this way, the probabilities are established and are used in the decision tree method.

The purpose of this paper is to elaborate on an integrated approach based on the multi-criteria methods and the decision tree method to select the suitable transport plan that takes into account the uncertainty of passenger flow, the needs of the passengers, and the capabilities of the railway operator.

The novelty of the proposed approach and its main contribution refers to the integration of the multi-criteria analysis, which defines the importance of the criteria and ranks the alternatives, and the decision tree method to determine the suitable transport plan for railway networks taking uncertainty into account. The output of the multi-criteria analysis serves as an input to the decision tree technique. 
The paper is structured as follows. Section 2 is the literature review. Section 3 presents the methodology. Section 4 shows the experimentation and results. Section 5 gives the conclusions. The elaborated methodology is applied for transport planning in Bulgaria's railway network.

\section{Literature Review}

Various authors applied multi-criteria decision-making methods to assess the criteria related to transport planning. Different multi-criteria methods used in transport systems and railway engineering were analyzed in $[1,2]$. The analytic hierarchy process (AHP) method was applied to investigate rail transit networks [3]. Financial, economic, system planning, and policy criteria were assessed. The model was experimented for Istanbul. The quality of passenger transportation by railway transport was analyzed by using the AHP method [4-6]. Lithuanian railways were analyzed using questionnaires referring to four groups of criteria: price of ticket, trip process planning and technology, train elements and the technical state of rails, safety. Forty-nine sub-criteria were investigated. The criteria of costs, comfort, accessibility to the stop, waiting time, riding time, maintenance and renewal of route were used in [7] to investigate the choice of the means of urban passenger transport. Two multi-criteria methods were used- ELimination Et Choice Translating Reality (ELECTRE) and AHP. Multi-criteria analysis was used in [8] to assess transportation investments. The AHP method and best worst method (BWM) are used for problem solving. Passenger services, environment, economics, urban planning, and architecture were determined as the main criteria. Travel cost, travel time, waiting time, suitability, accessibility, and safety were determined in [9] to assess public transport systems. An integrated multi-criteria approach based on the Delphi method, AHP, and Preference Ranking Organization METHod for Enrichment of Evaluations (PROMETHEE) method was applied in [9]. It was found out that the safety and suitability criteria were most important. The safety, rapidity, time, and comfort criteria were used in [10] to analyze the operation efficiency of the passenger transport. The integrated DEA-AHP model was studied. The multi-criteria methods analytic network process (ANP) and technique for order preference by similarity to ideal solution (TOPSIS) were used in [11] to evaluate alternative monorail routes. The economic, social, engineering, environmental impacts were applied to assess the alternatives. In [12], the authors assessed railway route planning based on the investment, costs, and number of trains criteria. The multi-criteria optimization and compromise solution (VIKOR) method was used.

Regression models were examined in [13] to assess the criteria affecting high-speed train services. The authors studied the criteria related to physical conditions, advertisements and information services, food service, personnel. Integer linear programming model and light robustness were proposed in [14] to investigate train timetabling and stop planning. The fuzzy AHP and rough AHP method were applied to investigate traffic accessibility [15]. The authors studied four groups of main criteria, such as transport, space, quality of service, system quality. The capacity utilization in the railway network was studied in [16]. The authors used criteria such as the length of railway network, number of trains per day, passenger and freight kilometers, punctuality of the trains to assess a ten-year period. An integrated neutrosophic set and the decision-making trial and evaluation laboratory (DEMATEL) multi-criteria method was elaborated on in [17] to choose the transport service provider.

The criteria for the quality of passenger rail transport were assessed using the full consistency method elaborated in [18]. The following importance of the defined criteria was establishedaccessibility, availability, security, time, customer care, information, comfort, and environmental impact. In [19], the authors applied the criteria for evaluation of transport planning such as costs, travel time, safety, profitability, environmental friendliness. The ELECTRE III and AHP methods were applied. The criteria of comfort and cleanness, service accessibility, information availability, service organization, staff behavior, behavior of inspectors, and costs were applied in [20] to establish the service quality of public transport. Factor analysis, segmentation analysis, and cluster analysis were used to study the customers and their quality perception. 
Some authors used fuzzy sets and multi-objective optimization for decision-making under uncertainty. The fuzzy AHP method makes it possible to take into account the uncertainty in decision-making. This approach was applied in [21] to determine a transport plan. The criteria of transport costs and car fleet were taken into account. The multi-criteria approach was applied to investigate a transportation system under uncertainty [22]. The authors defined social, environmental, and economic indicators and used the fuzzy AHP method to calculate the weights. The fuzzy AHP method was used to evaluate the railway timetable, [23]. The uncertain demand in passenger rail service was studied in [24]. A revenue-maximization model including operating costs for the rail operator and the value of time for passengers was studied by the authors. The authors used dynamic programming in the research. The fuzzy AHP method and Hurwitz method were applied to choose the best location of parking lots, taking into account the uncertainty of the investigated system [25]. Ranking of locations was done by means of the Hurwitz method.

The fuzzy PIvot Pairwise RElative Criteria Importance Assessment (F-PIPRECIA) and fuzzy evaluation based on distance from average solution (F-EDAS) methods were elaborated on in [26] with the purpose to select the best variant which allows the operator to make a profit. The model was tested for the organization of passenger railway traffic. The authors used the following criteria to assess variants for the organization of passenger traffic: budget, the capability of the operator, the effect, and the period of realization.

The decision tree technique allows for decision-making in the state of uncertainty when the selection of the best variant of action depends on the set of available possibilities. This method was applied to solve the alternative choice problem, to determine the important criteria for the mode of choice, to study public transport planning [27-31]. In [27], two methods were developed for the transportation planning process and mode choice analysis, one based on the decision tree and other based on a multinomial logit model. It was found out that the model based on decision tree was of higher accuracy compared to the multinomial logit models. In [28], the authors studied an expected-value-maximizing strategy and experimented with two types of probabilities in a decision tree, the first type can be modified independently; the second type are interrelated. The decision tree technique was used in [29] to investigate Izmir Transportation Master Plan. Twenty-five variables were selected which were divided into four groups: house information, person information, information of vehicle in trip, trip information. In [30], the authors studied an alternative choice problem on the basis of fuzzy decision trees. The decision tree method was applied to study public transport planning [31]. The following criteria were applied: safety, heading way, people comfort in the queue line, quality of the road in the busway corridor, and nonsterile bus lane. The decision tree approach was applied in [32] to assess urban transport. Criteria such as travel information, wayfinding information, time and movement, access, comfort and convenience, station attractiveness, safety and security, emergency situation handling, and overall satisfaction were studied. The decision tree method was applied in [33] to find the factors in regard to the delay of the trains.

It could be said that the main criteria that influence transport planning in related research are: travel time, traffic safety $[7,10,18,19,24,31]$; transport costs $[3,10,12,18,24]$; number of trains [12].

Different techniques were applied in the case of uncertainty, such as fuzzy sets and multi-objective optimization, fuzzy AHP method [21-23,25], fuzzy-PIPRECIA and fuzzy-EDAS method [26]; decision tree $[27,29,31-33]$. The decision tree approach was successfully used by the authors to select the best variant when the probabilities of the studied events are known.

Table 1 presents the methods used in literature sources on transport planning in the case of uncertainty. The main problems solved in related research concern transport planning, railway timetable planning, urban transport, public transport, railway passenger transport.

The multi-criteria methods using the fuzzy technique in the event of uncertainty are based on fuzzy numbers and complex computational procedures. The probabilities of passenger flow variation are not used in these methods. 
Table 1. Some of the methods used in literature sources on transport planning in the case of uncertainty.

\begin{tabular}{|c|c|c|c|}
\hline Methods Used & Area of Evaluation & Criteria Used & Author \\
\hline \multirow{4}{*}{ Fuzzy AHP } & \multirow{2}{*}{ Transport planning } & Transport costs; car fleet & [21] \\
\hline & & $\begin{array}{l}\text { Social, environmental, and economic } \\
\text { indicators }\end{array}$ & [22] \\
\hline & Railway timetable planning & $\begin{array}{l}\text { Weighted waiting times, average of waiting } \\
\text { time; ratio of waiting time to journey time }\end{array}$ & [23] \\
\hline & Assessment location of parking & Population, size, cost, distances & [25] \\
\hline $\begin{array}{l}\text { Fuzzy PIPRECIA and } \\
\text { Fuzzy EDAS }\end{array}$ & $\begin{array}{l}\text { Railway passenger transport } \\
\text { planning }\end{array}$ & $\begin{array}{l}\text { Budget, ability of the operator, effect of } \\
\text { realization, period of realization }\end{array}$ & [26] \\
\hline \multirow{5}{*}{ Decision tree } & Transport planning & $\begin{array}{l}\text { House information, person information, } \\
\text { information of vehicle in trip, trip } \\
\text { information }\end{array}$ & [29] \\
\hline & Urban transport planning & $\begin{array}{l}\text { Household size, number of vehicles, } \\
\text { income, age and of gender of traveller, } \\
\text { education level, type of employment, trip } \\
\text { purpose, travel time, cost }\end{array}$ & [27] \\
\hline & & $\begin{array}{l}\text { Travel information, wayfinding } \\
\text { information, time and movement, access, } \\
\text { comfort and convenience, station } \\
\text { attractiveness, safety and security, } \\
\text { emergency situation handling, and overall } \\
\text { satisfaction }\end{array}$ & [32] \\
\hline & Public transport planning & $\begin{array}{l}\text { Safety, heading way, people's comfort, } \\
\text { quality of the road }\end{array}$ & [31] \\
\hline & Assessment delay of the trains & Manner of driving & [33] \\
\hline Dynamic programming & $\begin{array}{l}\text { Railway passenger transport } \\
\text { planning }\end{array}$ & Operating costs, value of time & [24] \\
\hline
\end{tabular}

In most studies, the efforts of the authors were focused on issues related to uncertainty in the evaluation of criteria by experts, and for this reason, fuzzy models are preferred [21-23,25,26]. It could be concluded that the cases of uncertainty of passenger flow were not sufficiently studied.

The differences between the present study and other studies in related areas lies in the decision-making approach. This study combines the SIMUS method based on linear programming and weighted sum method to determine the appropriate alternative in a state of certainty for given parameters, the AHP method to determine the probabilities and the decision tree method for decision-making in the case of uncertainty. This research deploys a combination of three completely different methods, and thus introduces a new paradigm in multi-criteria decision-making. The probability-based decision-making approach allows for different transport demands to be taken into account. The appropriate alternative in this case is determined on the basis of the profit for each alternative in the different probability states.

In this paper, the SIMUS method was preferred since it does not use expert assessments, in order to evaluate the importance of criteria and rank the alternatives in the case of certainty.

\section{Materials and Methods}

Figure 1 illustrates the scheme of the methodology.

The proposed methodology consists of the following stages:

Stage 1. Forming the multi-criteria model taking into account uncertainty and risk.

Step 1. Determination of the criteria to assess the railway transport plan.

Step 2. Defining of the alternatives of the transport plan.

Step 3. Formulation the strategies of variation of passenger flow; determination of the probability variants of the strategies for change of passenger flow.

Stage 2: Determination of the input for the decision tree model.

Step 1. Determination of the probabilities of each event. In this step, the weights of each variant of passenger flow variation are calculated by applying the AHP method. 
Step 2. Determination of the profit of each alternative. The SIMUS method is used to rank the alternatives. The values of the criterion of the ranking are used as the profits.

Stage 3: Selection of suitable alternative applying the decision tree method. The criterion is the maximum of the expected value. The expected values are determined by using the results of the SIMUS and AHP method.

Stage 4: Verification of the results obtained by the decision tree method. A comparative analysis, using Laplace's criterion and Hurwitz's criterion, is performed.

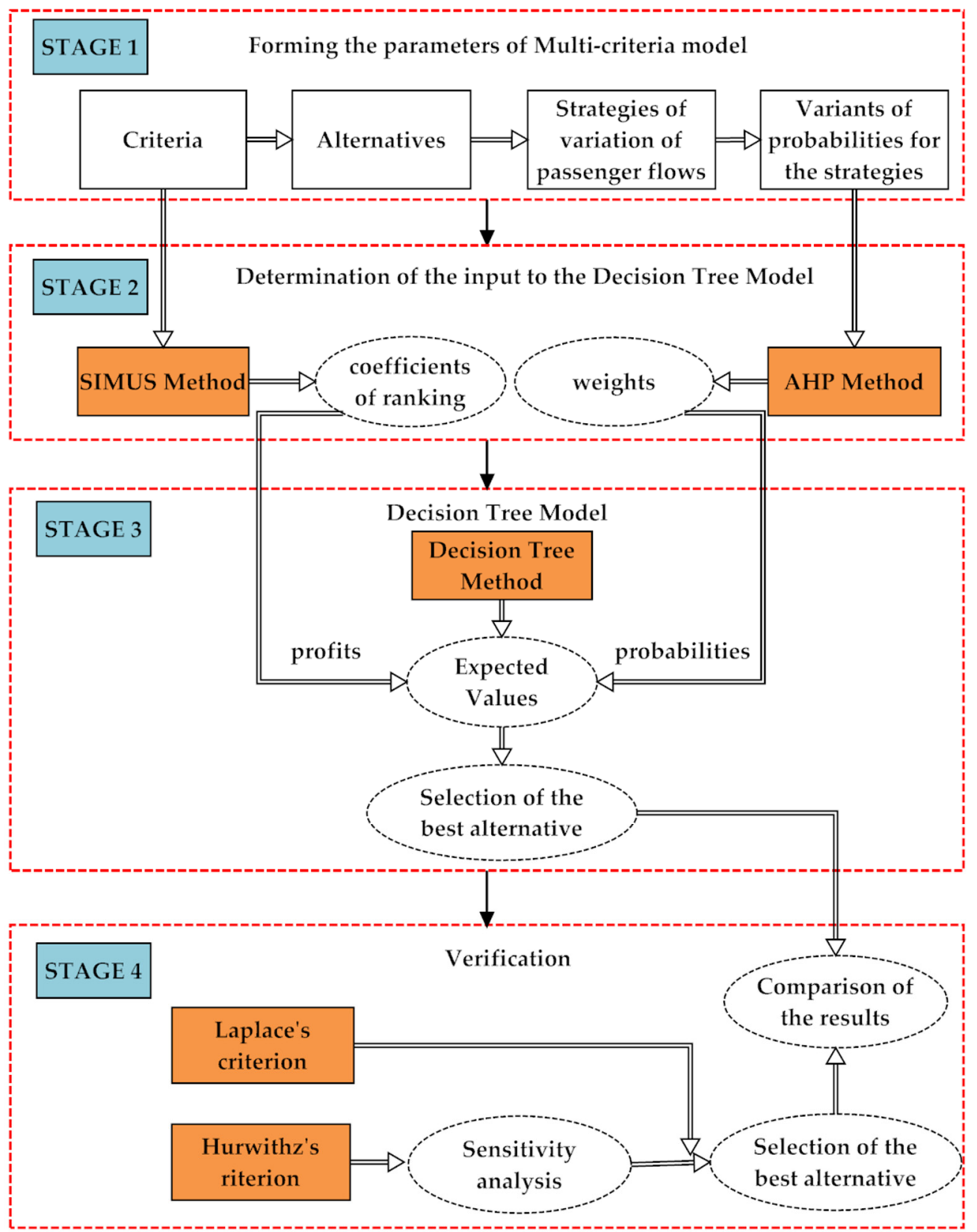

Figure 1. Scheme of methodology.

\subsection{First Stage: Parameters of the Multi-Criteria Model}

\subsubsection{Step 1: Defining the Criteria}

The first step defines the criteria to evaluate alternatives of the transport plan of intercity trains. The criteria were selected on the basis of an analysis of criteria used to assess transport in similar 
studies. The important criteria that influence transport planning in related research are: travel time [7,10,18,19,24,31]; transport costs [3,10,12,18,24]; number of trains [12]. Transport costs are an important indicator for the railway operator. Travel time and the number of trains are technological factors significant for passengers. The first indicator is related to the speed of transport; the second one shows the frequency of service. In this study, additional technological criteria related to passenger satisfaction are proposed. The aim of the passengers is to arrive at the final destination in the shortest possible time. This is achieved, for example, by direct trains with reduced stops, with an increase in operating speed. Passengers' expectations are for regular trains service throughout the day with sufficient capacity.

Taking into account the factors listed above the following criteria to assess the railway transport plan were determined in this research:

$C_{1}$-Frequency of services, pair trains/day. This criterion represents transport satisfaction of the passengers with railway services.

$C_{2}-$ Frequency of train stops. This criterion represents the average number of train stops.

$C_{3}-$ Average distance travelled, $\mathrm{km}$. This criterion represents the capability of the railway operator to offer long itineraries in the transport plan.

$\mathrm{C}_{4}$-Average operating speed, $\mathrm{km} / \mathrm{h}$. This criterion is a measure of the capability of the railway operator to provide fast transport services.

$C_{5}$-Reliability. This criterion is presented by a coefficient accounting for the average delay of trains. The coefficient is determined by dividing the number of delayed trains by the total number of trains. In this study, the delays are studied with a duration of up to $30 \mathrm{~min}$.

$\mathrm{C}_{6}$-Directness. It is represented the availability of direct service. The trains operate between big cities of over 100 thousand inhabitants without intermediate stops. The value of $C_{6}$ is 0 or 1 . If the alternative includes direct service: $C_{6}=1$, otherwise: $C_{6}=0$.

$C_{7}$-Train capacity, seats/day. This criterion is determined by the number of seats in train composition per day.

$C_{8}$ Direct operational costs, EUR/day. This factor shows the economic capabilities of the railway operator.

These criteria present two sides of the transport process: the capabilities of the railway operator and the requirements of passengers. The main criterion for railway operators, when they determine the transport plan, is operating costs. Speed, direct journey, frequency of service, and reliability are important factors for the quality of the transport service.

\subsubsection{Step 2: Determination of the Alternatives}

To determine the appropriate transport plan, it is necessary to compare the pre-defined alternatives. The number of alternatives is $i=1, \ldots, I$. The category of the trains, the number of wagons in the train, number of trains, and the routes are the parameters of the transport plan.

\subsubsection{Step 3: Determination of the Strategies and the Variants of Change in Passenger Flow}

The strategies are formed by the decision maker by setting the percentage change in passenger flow (reduction, preservation, or increase). This paper studies the following strategies: pessimistic strategy—reducing passenger traffic by $10 \%$; realistic strategy-keeping the flow of passengers; optimistic strategy-increase of passenger flow by $10 \%$. The reduction of the number of passengers could be, for example, due to various reasons, such as repair of the railway track, competitive road transport, reduced frequency, poor service. The increase in passenger traffic may be, for example, the result of increased frequency, improved attractiveness of rail transport, introduction of additional services, increased speed. The number of strategies is $k=1, \ldots, K$.

The variants of change of passenger flow are formed by setting probabilities for change of the passenger flow for the respective strategy. Since the strategies are three, each variant contains three numbers, the sum of which is equal to 1 . The variants and the strategies are presented as a matrix 
whose rows are equal to the number of strategies, and the number of columns is equal to the number of variants. The number of variants is $j=1, \ldots, J$. The variants of probabilities of passenger flow variation for each strategy are set by experts.

\subsection{Second Stage: Input for the Decision Tree Model}

\subsubsection{Step 1. Determination of the Weights of the Variants}

This study uses the AHP method to determine the weights of the variants of passenger flow variation. The AHP is a commonly used technique for multi-criteria analysis in decision-making. This method uses expert assessment. The weights are calculated based on the pair-wise comparison of the criteria by using a scale for assessing (Saaty's scale). Table A1 in Appendix A shows Saaty's scale $[34,35]$.

The result of the pairwise comparison of $n$ criteria can be summarized in an $(n, n)$ evaluation matrix where every element is the quotient of weights of the criteria.

The AHP method calculates the consistency ratio $C R$, as a measure of the expert assessments. Generally, if the $C R$ is less than 0.10 , the consistency of the decision-maker is considered satisfactory.

\subsubsection{Step 2: Ranking the Alternatives}

This study applies the SIMUS technique for ranking the alternatives of transport planning and for assessing the criteria. The SIMUS method uses linear programming, weighted sum, and outranking [36-38]. That method does not use experts to assess the criteria.

The application of the SIMUS starts with the formation of the decision matrix of criteria and alternatives. This matrix is normalized. The type of optimization, the type of restrictive conditions and their limits (RHS) are determined for each criterion This information is set at the end of the normalized matrix. The value of RHS could be determined in two ways: by the decision maker or according to the maximum or the minimum normalized value of the row. The maximum value of the row is chosen in case of a maximum of the objective function; the minimum value of the row is chosen in case of a minimum of objective function.

The linear optimization models for each criterion are formed and calculated. Each row of the decision matrix consistently is used as the objective functions. The restrictive conditions are formed by using the other rows of the matrix. The results of the optimization models represent the score of each alternative. They form the efficient results matrix (ERM).

The ranking of the alternatives is made on the basis of ERM. The criterion of ranking is determined according to the sum of all elements in each column (SC) of normalized ERM and the normalized values of the participation factor (PF). The PF represents the number of participations of each alternative in each column of the normalized ERM. The normalized values of PF are determined according to the number of criteria. The highest value of the criterion of ranking indicates the best alternative.

\subsection{Third Stage: Decision Tree Model}

The process of decision-making using a decision tree is multi-stage one where each stage is linked to the previous one and affects the next one. Through this method, management decisions can be made if the probabilities of achieving one or another result and the values of the different alternatives are known in advance.

The decision tree method uses a graphical representation of alternatives, probabilities, and profits, $[39,40]$. The probabilities of different events are determined in advance. In this paper, they are defined by the AHP method and are used as input to the decision tree. The concept of expected value is an integral part of the method of decision trees. In this study, the values of the criterion of ranking by the SIMUS method are used as input in expected values in the decision tree.

The criterion for choosing the best alternative by means of the decision tree method is the maximum of the expected value, depending on the type of explored criteria. 
In this study, the weights of passenger flow variation calculated with the AHP method represent the probabilities of the events. The values of the criterion of ranking by the SIMUS method represent the profit.

The expected value for each event showing the variants of passenger flow variation is calculated as follows:

$$
E V_{i j}=w_{j} \sum_{i=1}^{I} C_{E R M_{i k}} P_{j k}
$$

where $i=1, \ldots, I$ are the number of alternatives; $k=1, \ldots, K$ are the number of strategies of variation of passenger flow; $j=1, \ldots, J$ are the variants of probabilities of passenger flow variation for each strategy; $P_{j k}$ are the probabilities of passenger flow variation for variant $j$ and strategy $k ; w_{j}$ are the weights of the variants of passenger flow variation determined by the AHP method; $C_{E R M_{i k}}$ are the values of criterion of ranking by the SIMUS method for alternative $j$ and strategy $k ; w_{j}$ are the weights of the variants determined by using the AHP method; $P_{j k}$ are the probabilities for variant $j$ and strategy $k$ for variation of passenger flow.

The following conditions are met:

$$
\begin{gathered}
\sum_{j=1}^{J} w_{j}=1, \\
\sum_{k=1}^{K} P_{j k}=1, \text { for } \forall j .
\end{gathered}
$$

The Expected value for each alternative is determined as follows:

$$
E V_{i}=\max _{i} E V_{i j}
$$

The optimal alternative is determined according to the maximal value of the expected value of all alternatives:

$$
E V_{\text {opt }}=\max _{i} E V_{i}
$$

\subsection{Fourth Stage: Verification of the Results}

The verification of the results was conducted using Laplace's and Hurwitz's criteria [40]. The decision matrix includes the number of alternatives and the number of variants of passenger flow variation for the strategies. The elements of the decision matrix are calculated by the Equation (1):

$$
L_{i}=\frac{\sum_{j=1}^{J} E V_{i j}}{J} .
$$

The best alternative is determined through the maximum value of Laplace's criterion as $E V_{i j}$ presents the benefits:

$$
L_{\text {opt }}=\max _{i} L_{i}
$$

Hurwitz's criterion uses an additional coefficient $\alpha$. This coefficient permits making a decision in the different situations. The value of $\alpha$ has a value between 0 and 1. Generally, $\alpha=0.5$. While $\alpha=1$ represents an optimistic approach, $\alpha=0$ represents a pessimistic approach. Using $\alpha$, in a decision-making situation, the profit for each alternative is calculated.

The best alternative is determined by the maximum value of Hurwitz's criterion as $E V_{i j}$ presents the benefits:

$$
H_{i}=\alpha \max _{i} E V_{i j}+(1-\alpha) \min _{i} E V_{i j} .
$$

The alternative having maximum value of Hurwitz's criterion is selected, as $E V_{i j}$ presents the benefits:

$$
H_{\text {opt }}=\max _{i} H_{i}
$$




\section{Results and Discussion}

The approach presented here was applied to Bulgaria's railway network. The transport plan of intercity trains was studied.

This research was conducted under the following limitations:

The number of wagons in the train can be three or four. This limitation is determined by the current situation in the Bulgarian railway network.

The reduction and increase of passengers is $10 \%$. In this way, the strategies are formed.

The variants of passenger flow variation are formed on the basis of the assumption that the realistic strategy can have a probability between $20 \%$ and $50 \%$.

\subsection{Multi-Criteria Model}

\subsubsection{Alternatives}

The approach presented here was applied to Bulgaria's railway network. The transport plan of intercity trains was studied. This research investigates three types of passenger trains: Category 1-express; the passengers must have a reservation; Category 2-intercity trains, reservation is needed; Category 3-fast trains; reservation is not needed. Category 1 serves big transport and administrative centers. Category 2 serves big transport and administrative centers and also additionally big cities. Category 3 operates between additional intermediate stations.

Nine alternatives of a transport plan were studied. The alternatives were chosen taking into account train categories and also the number of wagons in the train compositions.

Table 2 shows the alternatives. Alternatives 1-3 include three categories of trains, Alternatives 4-9 include two categories of trains. For example, Alternative 1 contains the following parameters:

- Category 1 trains are formed of 4 wagons. These trains serve 3 itineraries in the railway network.

- Category 2 trains are formed of 4 wagons too. These trains serve 7 itineraries in the railway network.

- Category 3 trains are formed of 4 wagons too. These trains serve 17 itineraries in the railway network.

Table 2. Alternatives of transport plan.

\begin{tabular}{|c|c|c|c|c|c|c|c|c|c|c|c|}
\hline 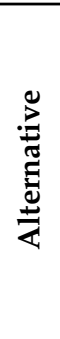 & 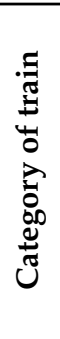 & 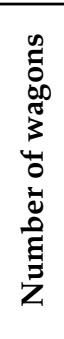 & 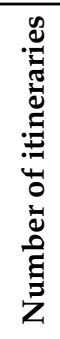 & 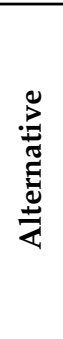 & 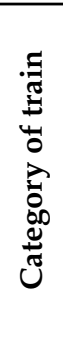 & 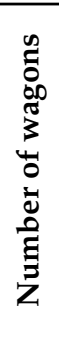 & 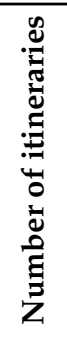 & 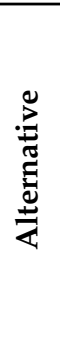 & 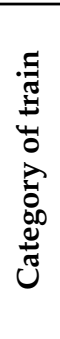 & 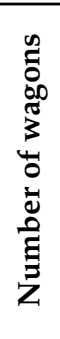 & 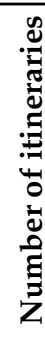 \\
\hline \multirow{3}{*}{1} & 1 & 4 & 3 & \multirow{3}{*}{4} & 1 & 4 & 3 & \multirow{3}{*}{7} & 1 & 0 & 0 \\
\hline & 2 & 4 & 7 & & 2 & 0 & 0 & & 2 & 4 & 7 \\
\hline & 3 & 4 & 17 & & 3 & 4 & 17 & & 3 & 4 & 17 \\
\hline \multirow{3}{*}{2} & 1 & 3 & 3 & \multirow{3}{*}{5} & 1 & 3 & 3 & \multirow{3}{*}{8} & 1 & 0 & 0 \\
\hline & 2 & 3 & 7 & & 2 & 0 & 0 & & 2 & 3 & 7 \\
\hline & 3 & 3 & 17 & & 3 & 3 & 17 & & 3 & 3 & 17 \\
\hline \multirow{3}{*}{3} & 1 & 3 & 3 & \multirow{3}{*}{6} & 1 & 3 & 3 & \multirow{3}{*}{9} & 1 & 0 & 0 \\
\hline & 2 & 4 & 7 & & 2 & 0 & 0 & & 2 & 3 & 7 \\
\hline & 3 & 4 & 17 & & 3 & 4 & 17 & & 3 & 4 & 17 \\
\hline
\end{tabular}

\subsubsection{Strategies and Variants of Passenger Flow Variations}

The strategies for changing the passenger flow were determined on the basis of an analysis of the passengers transported on Bulgaria's railway network for a ten-year period (2009-2019). Figure 2 shows 
the percentage change in passenger traffic compared to the previous year. For example, the reduction in passenger traffic in 2010 compared to 2009 is about 4\%; the increase in passenger traffic in 2019 compared to 2018 is also about $4 \%$. Figure 2 shows that the maximum decrease in the transported passengers is about $10 \%$.

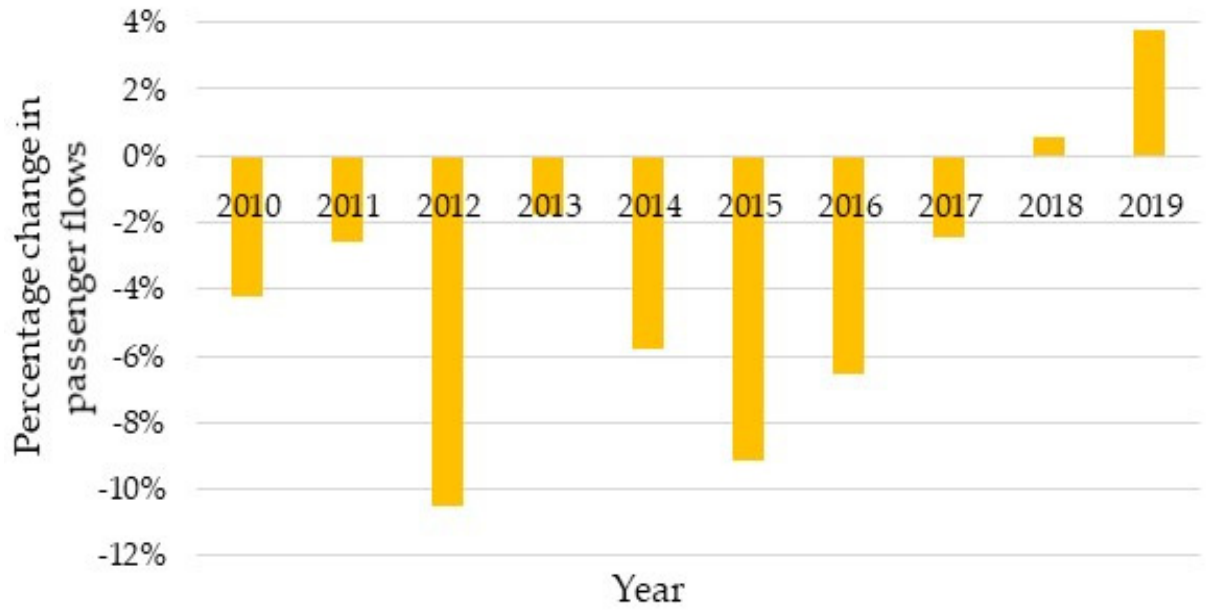

Figure 2. Percentage change in passenger traffic compared to the previous year.

The best transport plan was determined in the case of uncertainty of passenger flow.

This paper studies the following strategies: pessimistic strategy $(k=1)$-reducing passenger traffic by $10 \%$; realistic strategy $(k=2)$-keeping the flow of passengers; optimistic strategy $(k=3)$-increase passenger flow by $10 \%$.

Table 3 presents the variants investigated in this study. For example, variant 1 indicates that the probability of reduction in passenger flow by $10 \%$ is 0.4 ; the probability of preservation of passenger flow is 0.5 ; and the probability of increase in passenger flow by $10 \%$ is 0.1 . The variants are formed on the assumption that the realistic strategy can have a probability between $20 \%$ and $50 \%$.

Table 3. Variants of variation of passenger flow.

\begin{tabular}{|c|c|c|c|c|c|c|c|}
\hline \multirow{3}{*}{$\begin{array}{c}\text { Variant } \\
j\end{array}$} & \multirow{2}{*}{\multicolumn{3}{|c|}{$\begin{array}{c}\text { Probabilities of Change in Passenger Flow } \\
\text { Strategy, } k\end{array}$}} & \multirow{3}{*}{$\begin{array}{c}\text { Variant } \\
\quad j\end{array}$} & \multirow{2}{*}{\multicolumn{3}{|c|}{$\begin{array}{c}\text { Probabilities of Change in Passenger Flow } \\
\text { Strategy, } k\end{array}$}} \\
\hline & & & & & & & \\
\hline & 1 & 2 & 3 & & 1 & 2 & 3 \\
\hline 1 & 0.40 & 0.50 & 0.10 & 12 & 0.50 & 0.30 & 0.20 \\
\hline 2 & 0.10 & 0.50 & 0.40 & 13 & 0.20 & 0.30 & 0.50 \\
\hline 3 & 0.30 & 0.50 & 0.20 & 14 & 0.60 & 0.30 & 0.10 \\
\hline 4 & 0.20 & 0.50 & 0.30 & 15 & 0.10 & 0.30 & 0.60 \\
\hline 5 & 0.10 & 0.40 & 0.50 & 16 & 0.30 & 0.20 & 0.50 \\
\hline 6 & 0.50 & 0.40 & 0.10 & 17 & 0.50 & 0.20 & 0.30 \\
\hline 7 & 0.20 & 0.40 & 0.40 & 18 & 0.40 & 0.20 & 0.40 \\
\hline 8 & 0.40 & 0.40 & 0.20 & 19 & 0.60 & 0.20 & 0.20 \\
\hline 9 & 0.30 & 0.40 & 0.30 & 20 & 0.20 & 0.20 & 0.60 \\
\hline 10 & 0.30 & 0.30 & 0.40 & 21 & 0.70 & 0.20 & 0.10 \\
\hline 11 & 0.40 & 0.30 & 0.30 & 22 & 0.10 & 0.20 & 0.70 \\
\hline
\end{tabular}

\subsection{Decision Tree Model}

\subsubsection{Weights of the Variants of Passenger Flow Variation}

The weights of passenger flow variation variants were determined by using the AHP method. For this purpose, six experts including three specialists from academia and three specialists from BDZ Passengers service LTD, made a group assessment of the variants using Saaty's scale 1-9, (Table A1 in the Appendix A). Table 4 presents the pairwise comparisons. The end column of Table 4 shows the weights of the variants. 
Table 4. Variants of passenger flow variation. Consistency $C R=0.03$.

\begin{tabular}{|c|c|c|c|c|c|c|c|c|c|c|c|c|c|c|c|c|c|c|c|c|c|c|c|}
\hline \multirow{2}{*}{$j$} & \multicolumn{22}{|c|}{ Variants of Passenger Flow Variation for the Strategies } & \multirow{2}{*}{$w_{j}$} \\
\hline & 1 & 2 & 3 & 4 & 5 & 6 & 7 & 8 & 9 & 10 & 11 & 12 & 13 & 14 & 15 & 16 & 17 & 18 & 19 & 20 & 21 & 22 & \\
\hline 1 & 1 & 1 & 1 & 1 & 1 & 2 & 2 & 1 & 1 & 2 & 1 & 2 & 2 & 2 & 2 & 2 & 3 & 2 & 2 & 2 & 2 & 1 & 0.065 \\
\hline 2 & 1 & 1 & 1 & 1 & 1 & 2 & 1 & 1 & 1 & 2 & 1 & 2 & 2 & 2 & 2 & 2 & 3 & 2 & 2 & 2 & 2 & 2 & 0.063 \\
\hline 3 & 1 & 1 & 1 & 1 & 2 & 1 & 1 & 2 & 1 & 2 & 1 & 1 & 2 & 2 & 2 & 2 & 3 & 2 & 2 & 2 & 2 & 2 & 0.063 \\
\hline 4 & 1 & 1 & 1 & 1 & 2 & 2 & 2 & 1 & 2 & 1 & 2 & 2 & 2 & 2 & 2 & 2 & 3 & 2 & 2 & 2 & 2 & 2 & 0.070 \\
\hline 5 & 1 & 1 & 0.5 & 0.5 & 1 & 0.5 & 1 & 0.5 & 0.33 & 1 & 1 & 0.5 & 1 & 1 & 1 & 1 & 2 & 1 & 1 & 2 & 2 & 1 & 0.039 \\
\hline 6 & 0.5 & 0.5 & 1 & 0.5 & 2 & 1 & 0.5 & 1 & 2 & 1 & 1 & 1 & 0.5 & 1 & 0.5 & 0.5 & 1 & 1 & 1 & 0.5 & 1 & 2 & 0.040 \\
\hline 7 & 0.5 & 1 & 1 & 0.5 & 1 & 2 & 1 & 2 & 0.5 & 0.5 & 1 & 2 & 1 & 2 & 2 & 2 & 2 & 1 & 2 & 2 & 2 & 2 & 0.056 \\
\hline 8 & 1 & 1 & 0.5 & 1 & 2 & 1 & 0.5 & 1 & 1 & 2 & 1 & 1 & 2 & 2 & 2 & 2 & 1 & 2 & 2 & 2 & 2 & 2 & 0.057 \\
\hline 9 & 1 & 1 & 1 & 0.5 & 3 & 0.5 & 2 & 1 & 1 & 2 & 2 & 2 & 2 & 2 & 2 & 2 & ? & 0 & 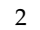 & 2 & 2 & 2 & 0.067 \\
\hline 10 & 0.5 & 0.5 & 0.5 & 1 & 1 & 1 & 2 & 0.5 & 0.5 & 1 & 1 & 1 & 1 & 2 & 2 & 2 & 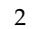 & 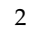 & 2 & 2 & 2 & 2 & 0.052 \\
\hline 11 & 1 & 1 & 1 & 0.5 & 1 & 1 & 1 & 1 & 0.5 & 1 & 1 & 3 & 3 & 3 & 3 & 1 & 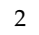 & 1 & 1 & 1 & 1 & 2 & 0.054 \\
\hline 12 & 0.5 & 0.5 & 1 & 0.5 & 2 & 1 & 0.5 & 1 & 0. & 1 & 0.33 & 1 & 2 & 2 & 2 & 2 & 2 & 2 & 2 & 2 & 2 & 2 & 0.050 \\
\hline 13 & 0.5 & 0.5 & 0.5 & 0.5 & 1 & 2 & 1 & 0.5 & 0.5 & 1 & 0. & 0.5 & 1 & 1 & 0.5 & 0.5 & 1 & 1 & 1 & 0.5 & 0.5 & 1 & 0.031 \\
\hline 14 & 0.5 & 0.5 & 0.5 & 0.5 & 1 & 1 & 0.5 & 0.5 & 0.5 & 0.5 & 0.33 & 0.5 & 1 & 1 & 0.5 & 0.5 & 1 & 1 & 1 & 0.5 & 0.5 & 1 & 0.027 \\
\hline 15 & 0.5 & 0.5 & 0.5 & 0.5 & 1 & 2 & 0.5 & 0.5 & 0.5 & 0.5 & 0.33 & 0.5 & 2 & 2 & 1 & 1 & 2 & 2 & 2 & 2 & 2 & 2 & 0.042 \\
\hline 16 & 0.5 & 0.5 & 0.5 & 0.5 & 1 & 2 & 0.5 & 0.5 & 0.5 & 0.5 & 1 & 0.5 & 2 & 2 & 1 & 1 & 2 & 2 & 1 & 1 & 2 & 1 & 0.038 \\
\hline 17 & 0.5 & 0.33 & 0.33 & 0.33 & 0.5 & 1 & 0.5 & 1 & 0.5 & 0.5 & 0.5 & 0.5 & 1 & 1 & 0.5 & 0.5 & 1 & 1 & 1 & 0.5 & 1 & 0.5 & 0.028 \\
\hline 18 & 0.5 & 0.5 & 0.5 & 0.5 & 1 & 1 & 0.5 & 0.5 & 0.5 & 0.5 & 1 & 0.5 & 1 & 1 & 0.5 & 0.5 & 1 & 1 & 1 & 0.5 & 1 & 0.5 & 0.029 \\
\hline 19 & 0.5 & 0.5 & 0.5 & 0.5 & 1 & 1 & 0.5 & 0.5 & 0.5 & 0.5 & 1 & 0.5 & 1 & 1 & 0.5 & 1 & 1 & 1 & 1 & 1 & 1 & 1 & 0.030 \\
\hline 20 & 0.5 & 0.5 & 0.5 & 0.5 & 0.5 & 2 & 0.5 & 0.5 & 0.5 & 0.5 & 1 & 0.5 & 2 & 2 & 0.5 & 1 & 2 & 2 & 1 & 1 & 1 & 2 & 0.037 \\
\hline 21 & 0.5 & 0.5 & 0.5 & 0.5 & 0.5 & 1 & 0.5 & 0.5 & 0.5 & 0.5 & 1 & 0.5 & 2 & 2 & 0.5 & 0.5 & 1 & 1 & 1 & 1 & 1 & 0.5 & 0.029 \\
\hline 22 & 1 & 0.5 & 0.5 & 0.5 & 1 & 0.5 & 0.5 & 0.5 & 0.5 & 0.5 & 0.5 & 0.5 & 1 & 1 & 0.5 & 1 & 2 & 2 & 1 & 0.5 & 2 & 1 & 0.033 \\
\hline
\end{tabular}

\subsubsection{Ranking of the Alternatives}

The SIMUS method was applied consistently to rank the alternatives for each of the strategies. Table 5 shows the decision matrices containing criteria values for realistic strategy. Tables A2 and A3 in the Appendix A present the decision matrices for pessimistic and optimistic strategies.

Table 6 presents the way of formation of optimization models. It is formed of two parts. The first part consists of the normalized decision matrix for realistic strategy-keeping the flow of passengers. The second part presents the type of optimization (minimum or maximum), type of operator, and the upper limits to each criterion (RHS).

Table 5. Values of criteria for alternatives. Realistic Strategy $(k=2)$.

\begin{tabular}{|c|c|c|c|c|c|c|c|c|c|c|}
\hline \multirow{2}{*}{\multicolumn{2}{|c|}{$\begin{array}{c}\text { Criterion } \\
\quad i\end{array}$}} & \multicolumn{9}{|c|}{ Alternative, $j$} \\
\hline & & 1 & 2 & 3 & 4 & 5 & 6 & 7 & 8 & 9 \\
\hline$C_{1}$ & trains/day & 38 & 48 & 40 & 35 & 43 & 38 & 37 & 46 & 39 \\
\hline$C_{2}$ & number & 15.45 & 14.94 & 14.68 & 16.17 & 16.79 & 15.55 & 16.19 & 15.72 & 15.62 \\
\hline$C_{3}$ & $\mathrm{~km}$ & 336.47 & 342.1 & 333.88 & 347.17 & 357.63 & 349.16 & 330.14 & 333.72 & 330.82 \\
\hline$C_{4}$ & $\mathrm{~km} / \mathrm{h}$ & 63 & 64 & 63 & 63 & 63 & 63 & 63 & 63 & 63 \\
\hline$C_{5}$ & coef. & 0.132 & 0.135 & 0.134 & 0.133 & 0.142 & 0.132 & 0.125 & 0.130 & 0.124 \\
\hline$C_{6}$ & coef. & 1 & 1 & 1 & 1 & 1 & 1 & 0 & 0 & 0 \\
\hline$C_{7}$ & seats/day & 10,640 & 10,080 & 10,850 & 9800 & 9030 & 10,010 & 10,360 & 9660 & 10,150 \\
\hline$C_{8}$ & EUR/day & 26,374 & 29,263 & 26,902 & 24,937 & 27,425 & 26,157 & 25,419 & 27,647 & 25,683 \\
\hline
\end{tabular}

Table 6. Normalized decision matrix for realistic strategy $(k=2)$.

\begin{tabular}{|c|c|c|c|c|c|c|c|c|c|c|c|c|}
\hline \multirow{3}{*}{ Criterion } & \multicolumn{9}{|c|}{ Alternative $i$} & \multirow{3}{*}{ Action } & \multirow{3}{*}{ Operator } & \multirow{3}{*}{ RHS } \\
\hline & 1 & 2 & 3 & 4 & 5 & 6 & 7 & 8 & 9 & & & \\
\hline & $x_{1}$ & $x_{2}$ & $x_{3}$ & $x_{4}$ & $x_{5}$ & $x_{6}$ & $x_{7}$ & $x_{8}$ & $x_{9}$ & & & \\
\hline$C_{1}$ & 0.10 & 0.13 & 0.11 & 0.10 & 0.12 & 0.10 & 0.10 & 0.13 & 0.11 & $\max$ & $\leq$ & 0.13 \\
\hline$C_{2}$ & 0.11 & 0.11 & 0.10 & 0.11 & 0.12 & 0.11 & 0.11 & 0.11 & 0.11 & $\min$ & $\geq$ & 0.10 \\
\hline$C_{3}$ & 0.11 & 0.11 & 0.11 & 0.11 & 0.12 & 0.11 & 0.11 & 0.11 & 0.11 & $\max$ & $\leq$ & 0.12 \\
\hline$C_{4}$ & 0.11 & 0.11 & 0.11 & 0.11 & 0.11 & 0.11 & 0.11 & 0.11 & 0.11 & $\max$ & $\leq$ & 0.12 \\
\hline$C_{5}$ & 0.11 & 0.11 & 0.11 & 0.11 & 0.12 & 0.11 & 0.11 & 0.11 & 0.10 & $\min$ & $\geq$ & 0.10 \\
\hline$C_{6}$ & 0.17 & 0.17 & 0.17 & 0.17 & 0.17 & 0.17 & 0.00 & 0.00 & 0.00 & $\max$ & $\leq$ & 0.17 \\
\hline$C_{7}$ & 0.12 & 0.11 & 0.12 & 0.11 & 0.10 & 0.11 & 0.11 & 0.11 & 0.11 & $\max$ & $\leq$ & 0.12 \\
\hline$C_{8}$ & 0.11 & 0.12 & 0.11 & 0.10 & 0.11 & 0.11 & 0.11 & 0.12 & 0.11 & $\min$ & $\geq$ & 0.10 \\
\hline
\end{tabular}

$x_{1}, \ldots, x_{9}$ are the score of alternatives 
The value of RHS depends on the type of optimization. The maximum or the minimum normalized value of the row is used. In the first case, the objective of the criterion is a maximum; in the second case, it is a minimum.

The type of optimization is set for each objective. The data for compiling the optimization models are given in Table 5 .

For example, the first model is made for the criterion $C_{1}$. The objective function is:

$$
0.10 x_{2}+0.13 x_{2}+0.11 x_{3}+0.10 x_{4}+0.12 x_{5}+0.10 x_{6}+0.10 x_{7}+0.13 x_{8}+0.11 x_{9} \rightarrow \operatorname{Max},
$$

where $x_{i}$ are the scores of the alternatives.

The other rows of the matrix $\left(C_{2}\right.$ to $\left.C_{8}\right)$ serve to form the restrictive conditions. For example, the restrictive condition for $C_{2}$ is:

$$
0.11 x_{2}+0.11 x_{2}+0.10 x_{3}+0.11 x_{4}+0.12 x_{5}+0.11 x_{6}+0.11 x_{7}+0.11 x_{8}+0.11 x_{9} \geq 0.10 \text {. }
$$

The restrictive conditions for the other criteria are similarly formed.

For all variables, the following condition applies:

$$
0 \leq x_{1}, x_{2}, x_{3}, x_{4}, x_{5}, x_{6}, x_{7}, x_{8}, x_{9} \leq 1
$$

The optimization models are performed for all other criteria.

Table 7 demonstrates the normalized efficient results matrix by using the sum of the row method and the results of ERM ranking. $Z_{1}, \ldots, Z_{8}$ presents the target functions equivalent to criteria $C_{1}, \ldots, C_{8}$ for the linear optimization models in the SIMUS method. Each row presents the values of the scores of the alternatives according to the optimization model. For example, the results show that the second alternative has a score of 1 . The scores for all other alternatives are equal to zero. The objective that impacts the ranking the most are criteria: $C_{1}$ (frequency of services), $C_{3}$ (average distance travelled); $C_{7}$ (train's capacity), $C_{2}$ (frequency of train stops), and $C_{8}$ (direct operational costs). They are presented in bold in Table 7.

Table 7. Normalized efficient results matrix for realistic strategy $(k=2)$.

\begin{tabular}{cccccccccc}
\hline \multirow{2}{*}{ Objective } & \multicolumn{10}{c}{ Alternative $\boldsymbol{i}$} \\
\cline { 2 - 10 } & $\mathbf{1}$ & $\mathbf{2}$ & $\mathbf{3}$ & $\mathbf{4}$ & $\mathbf{5}$ & $\mathbf{6}$ & $\mathbf{7}$ & $\mathbf{8}$ & $\mathbf{9}$ \\
\hline$Z_{1}$ & 0.00 & $\mathbf{1 . 0 0}$ & 0.00 & 0.00 & 0.00 & 0.00 & 0.00 & 0.00 & 0.00 \\
$Z_{2}$ & 0.00 & 0.03 & $\mathbf{0 . 9 7}$ & 0.00 & 0.00 & 0.00 & 0.00 & 0.00 & 0.00 \\
$Z_{3}$ & 0.00 & 0.00 & 0.00 & 0.00 & $\mathbf{0 . 9 8}$ & 0.00 & 0.00 & 0.02 & 0.00 \\
$Z_{4}$ & 0.00 & 0.00 & 0.00 & 0.00 & 0.00 & 0.00 & 0.00 & 0.20 & 0.80 \\
$Z_{5}$ & 0.00 & 0.00 & 0.00 & 0.00 & 0.00 & 0.00 & 0.00 & 0.47 & 0.53 \\
$Z_{6}$ & 0.00 & 0.00 & 0.24 & 0.00 & 0.76 & 0.00 & 0.00 & 0.00 & 0.00 \\
$Z_{7}$ & 0.00 & 0.00 & $\mathbf{0 . 9 8}$ & 0.00 & 0.00 & 0.00 & 0.02 & 0.00 & 0.00 \\
$Z_{8}$ & 0.00 & 0.00 & 0.00 & $\mathbf{1 . 0 0}$ & 0.00 & 0.00 & 0.00 & 0.00 & 0.00 \\
\hline $\mathrm{SC}$ & 0.00 & 1.03 & 2.18 & 1.00 & 1.75 & 0.00 & 0.02 & 0.69 & 1.33 \\
$\mathrm{PF}$ & 0 & 2 & 3 & 1 & 2 & 0 & 1 & 3 & 2 \\
$\mathrm{NPF}$ & 0.00 & 0.25 & 0.38 & 0.13 & 0.25 & 0.00 & 0.13 & 0.38 & 0.25 \\
$=\mathrm{SC} \times \mathrm{NPF}$ & 0.00 & 0.26 & 0.82 & 0.13 & 0.44 & 0.00 & 0.00 & 0.26 & 0.33 \\
$C_{E R M_{i k} \text { Ranking }}$ & 8 & 5 & 1 & 7 & 2 & 9 & 7 & 4 & 3 \\
\hline
\end{tabular}

SC—-sum of all scores in each column, PF-participation factor, or how many times each alternative satisfies each objective, NPF-normalized participation factor, obtained as a ratio between the PF and total number of objectives; $C_{E R M_{i k}}$-criterion of the ranking; The most important criteria are in bold.

The results indicate that Alternative 3 is the most suitable one for a realistic strategy. The ranking for the pessimistic strategy and the optimistic strategy is determined in a similar way using the SIMUS method. Tables A4 and A5 in the Appendix A present the results of the ranking for the pessimistic and optimistic strategies. 
Figure 3 illustrates the ranking of the alternatives for the strategies on the basis of the SIMUS criterion $\left(C_{E R M_{i k}}\right)$. It could be seen that the best alternative for the studied strategies is different.

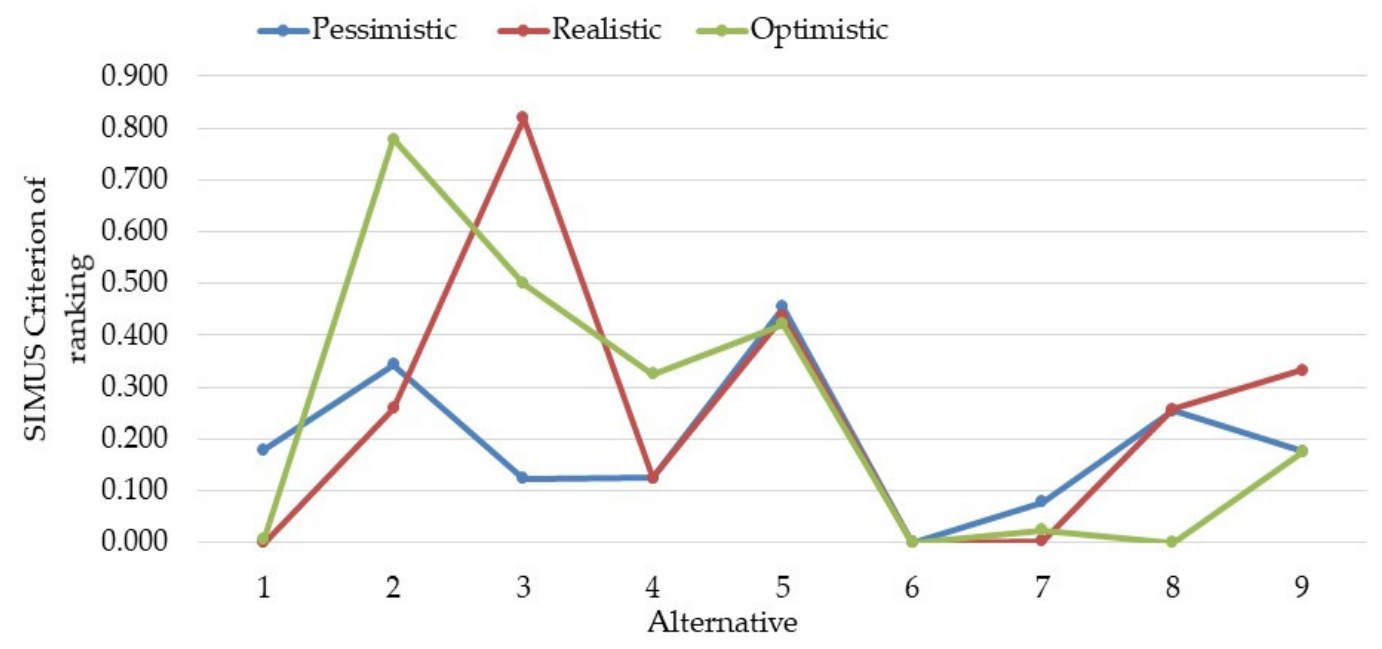

Figure 3. Ranking of the alternatives according the strategy.

Alternative 5 is the best for the pessimistic strategy; Alternative 2 is the best for the optimistic strategy; Alternative 3 is the best for the realistic strategy. These results are valid in a state of certainty. The number of trains, the categories, and the routes are different for each of the strategies. In this situation, the transport operator must change the organization of the trains in the railway network when passenger flow changes. This leads to instability in the transport plan and inconvenience for the users of the train services.

The uncertainty in transport planning is related to the fact that the decision maker cannot predict the probability of a change in passenger flow ( $10 \%$ reduction, saving, or $10 \%$ increase). For this purpose, this research deploys a combination of three completely different methods, and thus introduces a new paradigm in the multi-criteria decision-making process. The aim is to obtain a sustainable transport plan solution.

The values of the SIMUS ranking criterion are obtained on the basis of the scores of the objective function for each criterion. In this case, they could be accounted for as profits for each of the alternatives. This allows the values of the criterion of the ranking by the SIMUS method to be used as input to the decision tree in the case of uncertainty. The weights of the passenger flow variation variants determined using the AHP method are interpreted as probabilities and are also the input to the decision tree.

\subsubsection{Decision Tree}

The process of drawing a decision tree consists of three steps.

First, the tree starts in a chorological order. All the alternatives start marked in branches from the decision-making element denoted with a square. A decision event node, marked with a circle, is placed at the end of each alternative. The variants of variation of passenger flow for each strategy are connected with branches from each decision event node. At the end of each variant are placed additional nodes which denote the strategies. Each strategy is presented by a branch and is connected to the relevant node.

Second, once the tree is drawn, the final profits for each branch are determined and are placed at the end of each branch. The probability for the event is indicated. The values of the ranking criterion obtained using the SIMUS method for each alternative and strategy represents the possibilities.

Third, the tree is evaluated from right to left. The decision tree starts with a decision box having nine branches representing the nine alternatives of the transport plan. Each branch has twenty-two events or possibilities representing the number of variants of change of passenger flow. All the events are illustrated by circles. Each event has three branches representing the strategies of change in 
passenger flow. The probability of each strategy is indicated in the end of the branch. The values of the ranking criterion calculated by the SIMUS approach are presented on each of branches representing the strategies. The values of the weights of the variant determined using the AHP method are presented in the end of the branches.

Figure 4 presents the decision tree for the problem under study.

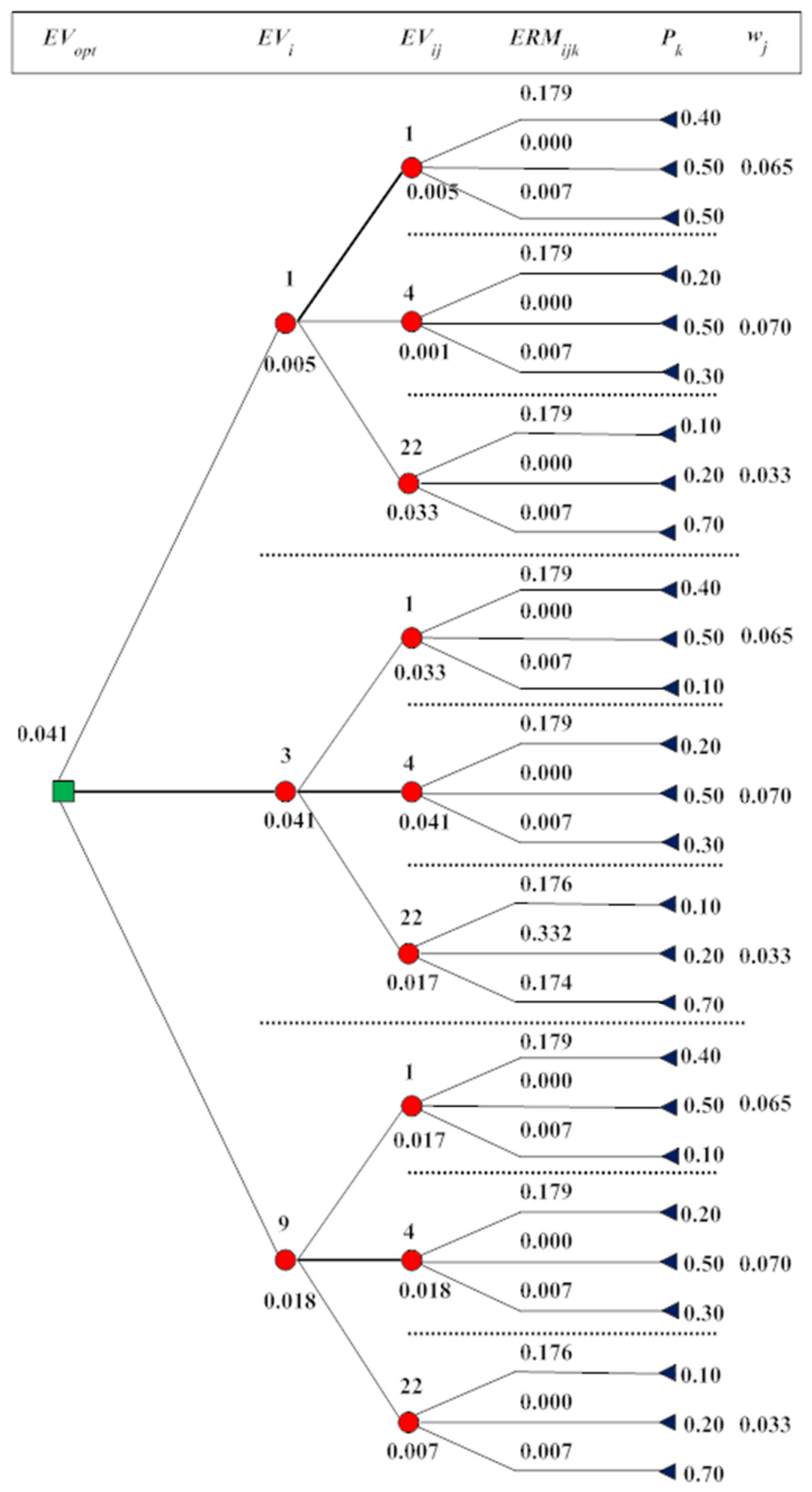

Figure 4. Decision tree.

The selection of the best alternative is performed in the following sequence. First, the values of expected values $E V_{i j}$ for each variant are calculated. The results are placed next to the event node 
presenting the variants. Second, for each alternative is determined the expected value and it is placed next to event node. Third, the optimal alternative is selected, according to the criterion maximum value of the expected value. The branch of the selected alternative that is connected with the decision-making element is marked with a thick line.

Table A6 in the Appendix A shows the value of the expected value for each variant of passenger flow variation and the alternative determined by Equation (4).

Figure 5 illustrates the comparison of the expected value for all alternatives according to the variants of passenger flow variation. It can be seen that the competing strategies are Alternatives 2, Alternative 3, and Alternative 5. Alternative 3 has the maximum value of the criterion for most of the variants. Alternative 2 is also the best for variants 15-22. Alternative 3, Alternative 2, and Alternative 5 have close results for variants 10 and 14. Alternative 6 has a value equal to zero for all variants. This is due to the value of the ranking criterion obtained using the SIMUS method which is equal to 0.

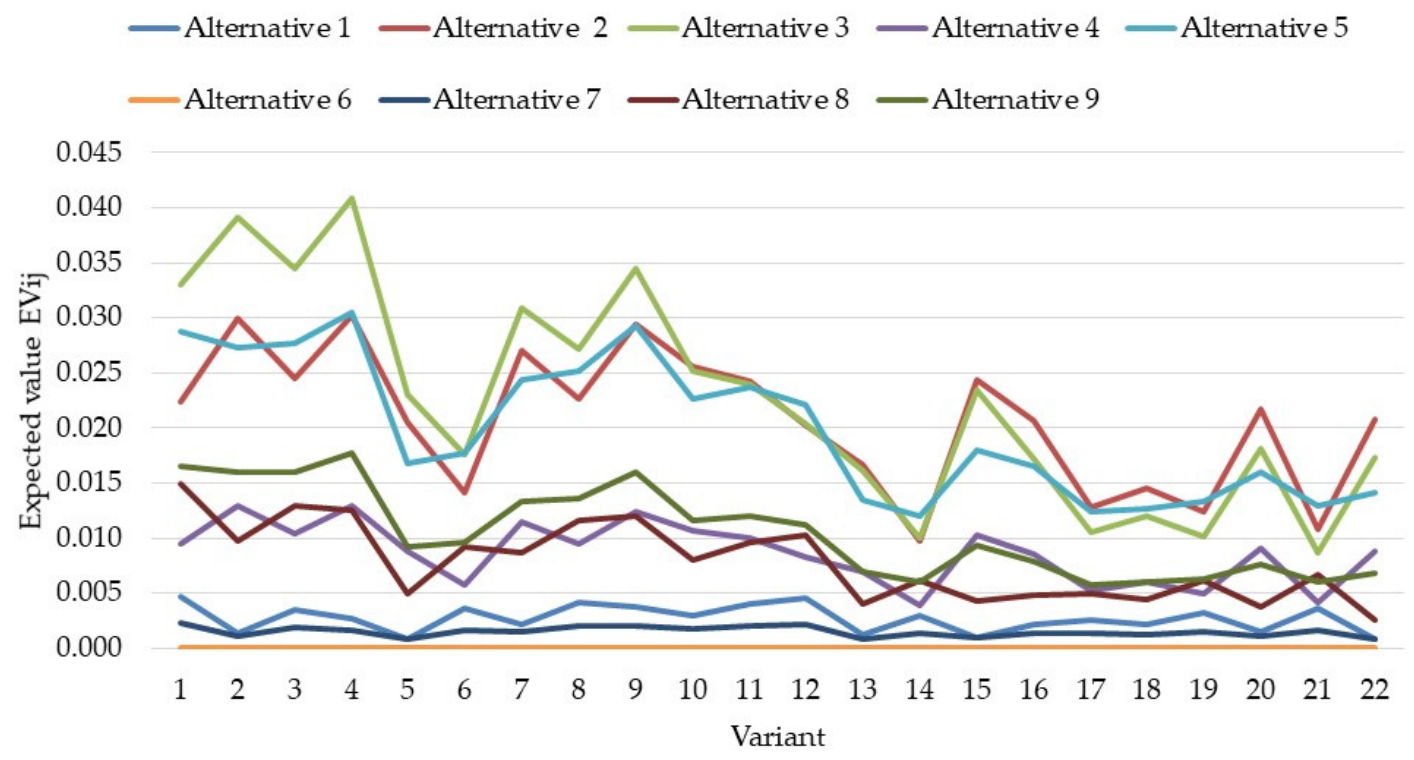

Figure 5. Expected value for each variant of passenger flow variation.

Figure 6 presents the expected value for alternatives, $E V_{i}$. The optimal solution is chosen according the maximum expected value. The results show that Alternative 3 is the best.

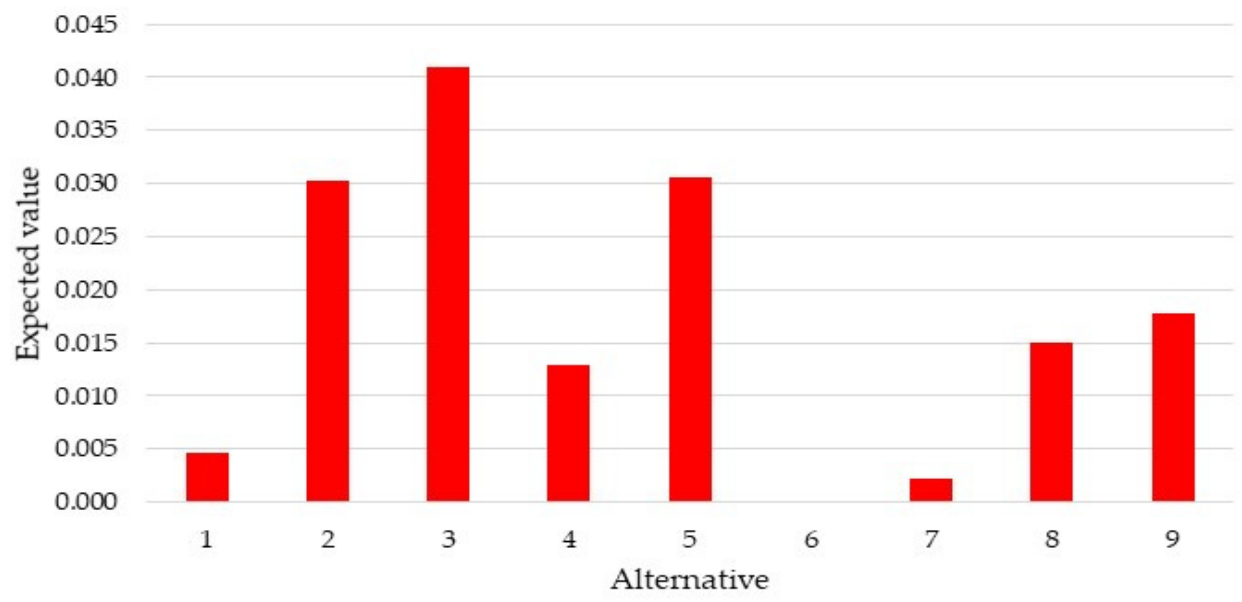

Figure 6. Expected value for alternatives.

The obtained solution makes it possible for the transport plan to be sustainable in the case of uncertainty with specified limitations and probabilistic change in passenger flow. The organization 
of passenger rail transport according to Alternative 3 includes express, intercity, and fast trains. The number of trains with decreasing and increasing passenger traffic is different. It can be seen in Table 5, Tables A2 and A3 in the Appendix A. In the case of keeping the passengers, the number of trains is 40 pairs per day; when there is a decrease in passengers, the number of trains is 38 pairs per day; when passengers increase, the number of trains is 42 pairs per day. The routes for all categories of trains remain unchanged.

Figure 7 illustrates the difference in operating costs for the best alternatives in the case of certainty or uncertainty. The first row below the abscissa shows the best alternatives for the state of certainty for the studied strategies; the second row indicates the best alternatives for the state of uncertainty for the strategies, and the third row represents the corresponding strategy for which the decision was made. It could be seen that obtained results for the case of uncertainty show a reduction in operating costs for the transport plan compared to the case of certainty. The obtained results make it possible for the transport operators to take not only planning decisions but also operational ones.

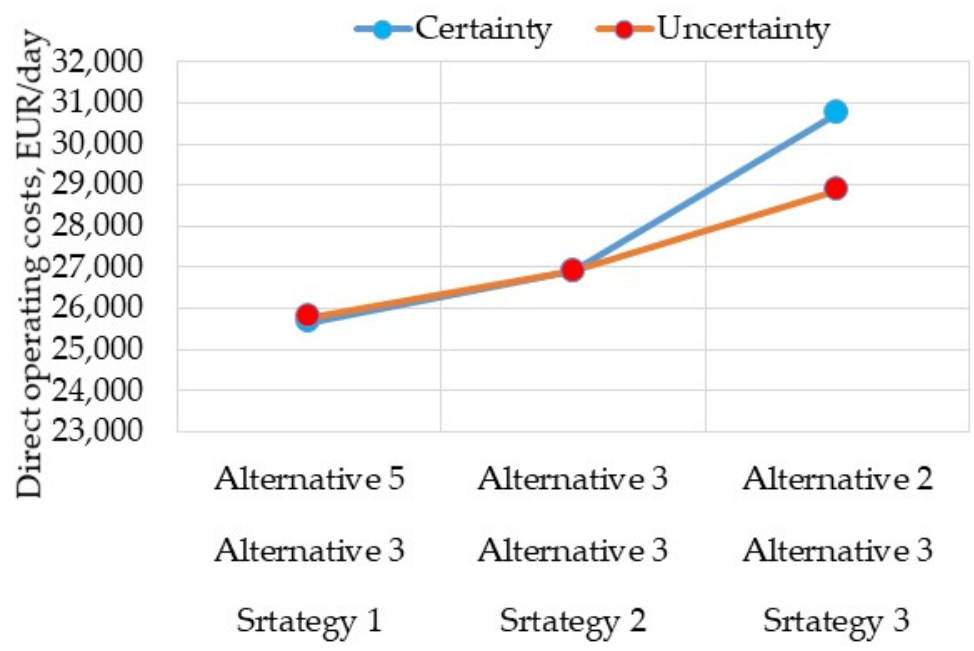

Figure 7. Direct operating costs in the case of certainty and uncertainty, EUR/day.

\subsection{Verification of the Results}

Laplace's criterion and Hurwitz's criterion were used to verify the results obtained through the decision tree method. Both criteria use data of the expected values determined by Equation (4) which are given in Table 8. Hurwitz's approach uses coefficient $\alpha$ to assess the best alternative in different preferences of decision-making. Alternative 3 is selected by means of Laplace's criterion as the best. Alternative 5 is in the second position with close values of Laplace's criterion.

Table 8. Parameters of Laplace's criterion and Hurwitz's criterion.

\begin{tabular}{|c|c|c|c|c|c|c|c|c|c|c|c|c|c|}
\hline \multirow{3}{*}{$\begin{array}{c}\text { Alternative } \\
i\end{array}$} & \multirow{3}{*}{$\begin{array}{l}\text { Laplace's } \\
\text { Criterion }\end{array}$} & \multirow{3}{*}{$\max _{i} E V_{i j}$} & \multirow{3}{*}{$\min _{i} E V_{i j}$} & \multicolumn{10}{|c|}{ Hurwitz's Criterion } \\
\hline & & & & \multicolumn{10}{|c|}{ Coefficient $\alpha$} \\
\hline & & & & 0.1 & 0.2 & 0.3 & 0.4 & 0.5 & 0.6 & 0.7 & 0.8 & 0.9 & 1 \\
\hline 1 & 0.003 & 0.005 & 0.001 & 0.001 & 0.002 & 0.002 & 0.002 & 0.003 & 0.003 & 0.004 & 0.004 & 0.004 & 0.005 \\
\hline 2 & 0.021 & 0.030 & 0.010 & 0.012 & 0.014 & 0.016 & 0.018 & 0.020 & 0.022 & 0.024 & 0.026 & 0.028 & 0.030 \\
\hline 3 & 0.022 & 0.041 & 0.009 & 0.012 & 0.015 & 0.018 & 0.022 & 0.025 & 0.028 & 0.031 & 0.034 & 0.038 & 0.041 \\
\hline 4 & 0.009 & 0.013 & 0.004 & 0.005 & 0.006 & 0.007 & 0.008 & 0.008 & 0.009 & 0.010 & 0.011 & 0.012 & 0.013 \\
\hline 5 & 0.020 & 0.031 & 0.012 & 0.014 & 0.016 & 0.018 & 0.019 & 0.021 & 0.023 & 0.025 & 0.027 & 0.029 & 0.031 \\
\hline 6 & 0.000 & 0.000 & 0.000 & 0.000 & 0.000 & 0.000 & 0.000 & 0.000 & 0.000 & 0.000 & 0.000 & 0.000 & 0.000 \\
\hline 7 & 0.001 & 0.002 & 0.001 & 0.001 & 0.001 & 0.001 & 0.002 & 0.002 & 0.002 & 0.002 & 0.003 & 0.003 & 0.003 \\
\hline 8 & 0.008 & 0.015 & 0.003 & 0.004 & 0.006 & 0.007 & 0.009 & 0.010 & 0.012 & 0.013 & 0.015 & 0.016 & 0.017 \\
\hline 9 & 0.011 & 0.018 & 0.006 & 0.008 & 0.009 & 0.011 & 0.013 & 0.015 & 0.016 & 0.018 & 0.020 & 0.022 & 0.024 \\
\hline
\end{tabular}

The results are similar to those obtained using the decision tree method. 
Figure 8 illustrates Hurwitz's criterion according to coefficient $\alpha$ for all alternatives. Hurwitz's criterion gives the opportunity to investigate the sensitivity of the results.

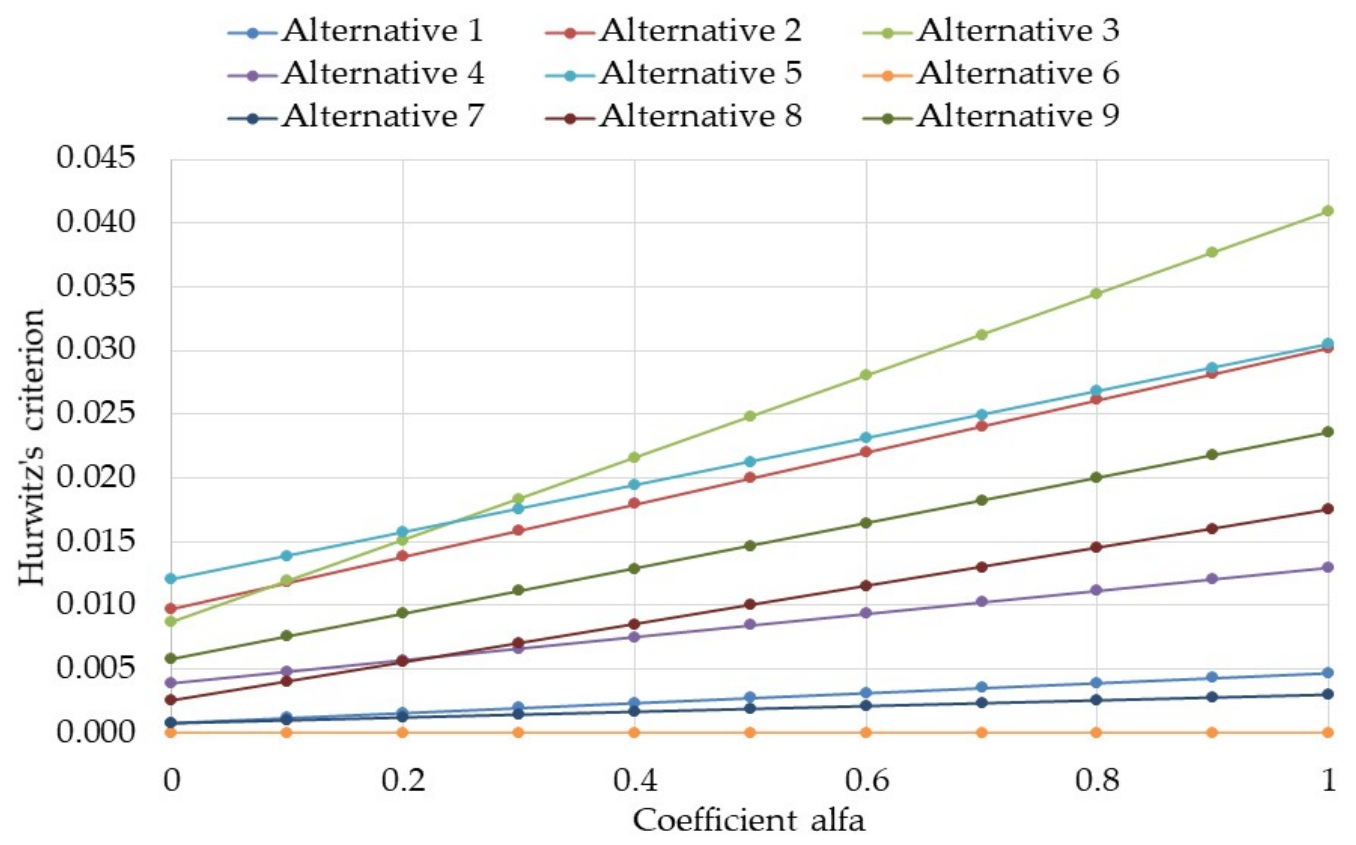

Figure 8. Hurwitz's criterion according to coefficient $\alpha$.

The value of coefficient $\alpha$ has been set between zero and one, with a step of 0.1. The value of coefficient $\alpha=0$ coincides with the minimum values of expected value $E V_{i j}$. The value of coefficient $\alpha=1$ represents the maximum values of expected value $E V_{i j}$. The value of $\alpha=0.5$ could be taken as representing a balanced approach. It could be seen that Alternative 3 is the suitable one for most of the coefficient $\alpha$ values (from 0.26 to 1 ). Alternative 5 is the best for values of coefficient $\alpha$ from 0 to 0.24 . Both alternatives have equal results for value of the coefficient $\alpha=0.25$. The results obtained with Hurwitz's criterion are similar to those obtained through the decision tree method. On the basis of the analysis performed, the implementation of Alternative 3 is recommended as the most acceptable solution.

\section{Conclusions}

This paper proposes an integrated model for planning railway passenger transport in the case of uncertainty based on SIMUS, AHP, and decision tree methods. This research introduces a new paradigm in multi-criteria decision-making

Eight quantitative and qualitative criteria accounting for passenger satisfaction and the capabilities of the transport company were defined to assess the transport plan. Nine alternatives for the Bulgarian railway network have been tested. The uncertainty of passenger flow was studied. Pessimistic, realistic, and optimistic strategies of variation of passenger flow were investigated. An increase or a decrease of $10 \%$ in passenger flow was established on the basis of an analysis of passengers transported for a ten-year period. This shows the actual state of transport demand and also the practicability of the obtained results. The SIMUS method based on linear programming was applied to rank the alternatives of the transport plan for each of the strategies. It was found out that the criteria that impact the ranking the most are frequency of services, average distance travelled, train's capacity, frequency of train stops, and direct operational costs. The twenty-two variants of probability of change in passenger flow under the respective strategy were studied. Their weights were determined by experts' assessments using the AHP method and were applied as input to the decision tree model. 
The best strategy was selected by using the decision tree method. A verification was performed by comparing the results with Laplace's criterion and Hurwitz's criterion. It was found out that the ranking based on both criteria was similar to that of the decision tree method. The sensitivity analysis based on Hurwitz's criterion has been met. It was found out the stability of the choice of suitable alternative.

The theoretical contributions of this paper are based on the elaboration of the integration of multi-criteria methods with the decision tree method to account for uncertainty of passenger flow.

The practical contribution of this study involves the determination of a suitable transport plan (presented by Alternative 3) for the Bulgarian railway network. This alternative offers a transport plan including express intercity trains, intercity trains, and fast trains. This transport scheme includes 27 routes in the railway network. It was found out that the obtained results for the case of uncertainty show a reduction in operating costs for the transport plan compared to the one in the case of certainty.

The results could be used to compare different alternatives in the case of various variations in passenger flow. The proposed integrated approach could be used to investigate some areas or sections of a railway network and also transport corridors. By applying this elaborated approach, it is possible to achieve a benefit for passengers and carriers as well as to improve the quality of transport and the effectiveness of operating costs in the case of uncertainty.

The novelty of this study and its main advantage is the establishment of important objectives for the ranking; the integration of the SIMUS method and AHP method with the decision tree method is a complex approach for decision-making in a state of uncertainty. The methodology makes it possible to study different strategies and variants of variation of passenger flow.

The elaborated integrated approach could serve for making decisions about passenger trains planning in the case of uncertainty in passenger flow and about route planning; to study additional routes; to investigate different strategies of passenger flow variation; to make decisions in case of instability of passenger flow or lack of sufficient travel data.

Future research will expand the scope of the studied strategies of variation of passenger flow; analyze the uncertainty of passenger traffic on railway sections in case of traffic interruption due to repair works; investigate other parameters of the transport process under uncertainty, such as the capacity of trains and implementation of the proposed alternative.

Funding: This work was supported by the National Science Fund of the Ministry of Education and Science of Bulgaria [project numbers No.KП-06-H27/12 of 11.12.2018 "Modelling and elaboration of complex system for selection of transport technology in transport network"].

Acknowledgments: The author expresses her gratitude to "BDZ Passenger Services" Ltd. for providing the data used in this study.

Conflicts of Interest: The author declares no conflict of interest

\section{Appendix A}

Table A1. Saaty's scale for pair-wise comparison.

\begin{tabular}{ccc}
\hline Explanation & Intensity of Importance & Reciprocal Values \\
\hline Equal importance & 1 & 1 \\
Moderate importance & 3 & $1 / 3$ \\
Strong importance & 5 & $1 / 5$ \\
Very strong importance & 7 & $1 / 7$ \\
Extreme importance & 9 & $1 / 9$ \\
Average intermediate values & $2 ; 4 ; 6 ; 8$ & $1 / 2 ; 1 / 4 ; 1 / 6 ; 1 / 8$ \\
\hline
\end{tabular}


Table A2. Values of criteria for alternatives. Pessimistic strategy $(k=1)$.

\begin{tabular}{ccccccccccc}
\hline \multirow{2}{*}{ Criterion $\boldsymbol{i}$} & \multicolumn{10}{c}{ Alternative, $\boldsymbol{j}$} \\
\cline { 3 - 11 } & $\mathbf{1}$ & $\mathbf{2}$ & $\mathbf{3}$ & $\mathbf{4}$ & $\mathbf{5}$ & $\mathbf{6}$ & $\mathbf{7}$ & $\mathbf{8}$ & $\mathbf{9}$ \\
\hline$C_{1}$ & trains/day & 36 & 42 & 38 & 31 & 40 & 35 & 34 & 41 & 37 \\
$C_{2}$ & number & 15.36 & 14.88 & 15.21 & 15.94 & 16.3 & 15.63 & 16.32 & 16.02 & 15.62 \\
$C_{3}$ & $\mathrm{~km}$ & 327 & 344 & 335 & 350 & 361 & 355 & 335 & 335 & 331 \\
$C_{4}$ & $\mathrm{~km} / \mathrm{h}$ & 63 & 64 & 63 & 63 & 63 & 63 & 63 & 62 & 63 \\
$C_{5}$ & coef. & 0.132 & 0.135 & 0.134 & 0.133 & 0.142 & 0.132 & 0.125 & 0.130 & 0.124 \\
$C_{6}$ & coef. & 1 & 1 & 1 & 1 & 1 & 1 & 0 & 0 & 0 \\
$C_{7}$ & seats/day & 10,080 & 8820 & 10360 & 8680 & 8400 & 9240 & 9520 & 8610 & 9660 \\
$C_{8}$ & EUR/day & 24,404 & 25,672 & 25,777 & 22,198 & 25,664 & 24,436 & 23,603 & 24,806 & 24,522 \\
\hline
\end{tabular}

Table A3. Values of criteria for alternatives. Optimistic strategy $(k=3)$.

\begin{tabular}{ccccccccccc}
\hline \multirow{2}{*}{ Criterion $\boldsymbol{i}$} & \multicolumn{8}{c}{ Alternative, $\boldsymbol{j}$} \\
\cline { 3 - 11 } & $\mathbf{1}$ & $\mathbf{2}$ & $\mathbf{3}$ & $\mathbf{4}$ & $\mathbf{5}$ & $\mathbf{6}$ & $\mathbf{7}$ & $\mathbf{8}$ & $\mathbf{9}$ \\
\hline$C_{1}$ & trains/day & 40 & 51 & 42 & 36 & 48 & 41 & 38 & 47 & 40 \\
$C_{2}$ & number & 14.85 & 15.08 & 14.36 & 16.21 & 16.18 & 15.63 & 16.23 & 15.78 & 15.79 \\
$C_{3}$ & $\mathrm{~km}$ & 339.95 & 337.22 & 344.33 & 349.92 & 354.33 & 358.61 & 335.82 & 336.11 & 336.2 \\
$C_{4}$ & $\mathrm{~km} / \mathrm{h}$ & 64 & 64 & 64 & 63 & 63 & 64 & 63 & 63 & 63 \\
$C_{5}$ & coef. & 0.132 & 0.135 & 0.134 & 0.133 & 0.142 & 0.132 & 0.125 & 0.130 & 0.124 \\
$C_{6}$ & coef. & 1 & 1 & 1 & 1 & 1 & 1 & 0 & 0 & 0 \\
$C_{7}$ & seats/day & 11,200 & 10,710 & 11410 & 10,080 & 10,080 & 10,780 & 10,640 & 9870 & 10,430 \\
$C_{8}$ & EUR/day & 27,782 & 30,751 & 28,874 & 25,916 & 30,257 & 28,930 & 26,571 & 28,473 & 26,835 \\
\hline
\end{tabular}

Table A4. Normalized efficient results matrix for pessimistic strategy $(k=1)$.

\begin{tabular}{cccccccccc}
\hline \multirow{2}{*}{ Objective } & \multicolumn{10}{c}{ Alternative $\boldsymbol{i}$} \\
\cline { 2 - 10 } & $\mathbf{1}$ & $\mathbf{2}$ & $\mathbf{3}$ & $\mathbf{4}$ & $\mathbf{5}$ & $\mathbf{6}$ & $\mathbf{7}$ & $\mathbf{8}$ & $\mathbf{9}$ \\
\hline$Z_{1}$ & 0.00 & 0.00 & 0.00 & 0.00 & 0.00 & 0.00 & 0.00 & $\mathbf{1 . 0 0}$ & 0.00 \\
$Z_{2}$ & 0.00 & $\mathbf{1 . 0 0}$ & 0.00 & 0.00 & 0.00 & 0.00 & 0.00 & 0.00 & 0.00 \\
$Z_{3}$ & 0.00 & 0.00 & 0.00 & 0.00 & $\mathbf{0 . 9 8}$ & 0.00 & 0.00 & 0.02 & 0.00 \\
$Z_{4}$ & 0.55 & 0.37 & 0.00 & 0.00 & 0.00 & 0.00 & 0.00 & 0.00 & 0.08 \\
$Z_{5}$ & 0.00 & 0.00 & 0.00 & 0.00 & 0.00 & 0.00 & 0.62 & 0.00 & 0.38 \\
$Z_{6}$ & 0.17 & 0.00 & 0.00 & 0.00 & 0.83 & 0.00 & 0.00 & 0.00 & 0.00 \\
$Z_{7}$ & 0.00 & 0.00 & $\mathbf{0 . 9 8}$ & 0.00 & 0.00 & 0.00 & 0.00 & 0.00 & 0.02 \\
$Z_{8}$ & 0.00 & 0.00 & 0.00 & $\mathbf{1 . 0 0}$ & 0.00 & 0.00 & 0.00 & 0.00 & 0.00 \\
\hline SC & 0.72 & 1.37 & 0.98 & 1.00 & 1.82 & 0.00 & 0.00 & 1.02 & 0.47 \\
PF & 2 & 2 & 1 & 1 & 2 & 0 & 1 & 2 & 3 \\
NPF & 0.25 & 0.25 & 0.13 & 0.13 & 0.25 & 0.00 & 0.13 & 0.25 & 0.38 \\
S SC $\times$ NPF & 0.18 & 0.34 & 0.12 & 0.13 & 0.45 & 0.00 & 0.08 & 0.25 & 0.18 \\
Ranking & 4 & 2 & 7 & 6 & 1 & 9 & 8 & 3 & 5 \\
\hline$C_{E R M y y y y y y}$
\end{tabular}

$\mathrm{SC}$ - sum of all scores in each column, $\mathrm{PF}$ - participation factor, or how many times each alternative satisfies each objective, NPF-normalized participation factor, obtained as a ratio between the PF and total number of objectives; $C_{E R M_{i k}}$-criterion of the ranking; The most important criteria are in bold.

Table A5. Normalized efficient results matrix for optimistic strategy $(k=3)$.

\begin{tabular}{cccccccccc}
\hline \multirow{2}{*}{ Objective } & \multicolumn{10}{c}{ Alternative $\boldsymbol{i}$} \\
\cline { 2 - 10 } & $\mathbf{1}$ & $\mathbf{2}$ & $\mathbf{3}$ & $\mathbf{4}$ & $\mathbf{5}$ & $\mathbf{6}$ & $\mathbf{7}$ & $\mathbf{8}$ & $\mathbf{9}$ \\
\hline$Z_{1}$ & 0.00 & $\mathbf{1 . 0 0}$ & 0.00 & 0.00 & 0.00 & 0.00 & 0.00 & 0.00 & 0.00 \\
$Z_{2}$ & 0.00 & 0.00 & $\mathbf{1 . 0 0}$ & 0.00 & 0.00 & 0.00 & 0.00 & 0.00 & 0.00 \\
$Z_{3}$ & 0.00 & 0.00 & 0.00 & 0.00 & $\mathbf{0 . 9 8}$ & 0.00 & 0.00 & 0.00 & 0.02 \\
$Z_{4}$ & 0.06 & 0.76 & 0.00 & 0.00 & 0.00 & 0.00 & 0.18 & 0.00 & 0.00 \\
$Z_{5}$ & 0.00 & 0.32 & 0.00 & 0.00 & 0.00 & 0.00 & 0.00 & 0.00 & 0.68 \\
$Z_{6}$ & 0.00 & 0.00 & 0.00 & 0.30 & 0.70 & 0.00 & 0.00 & 0.00 & 0.00 \\
$Z_{7}$ & 0.00 & 0.00 & $\mathbf{1 . 0 0}$ & 0.00 & 0.00 & 0.00 & 0.00 & 0.00 & 0.00 \\
$Z_{8}$ & 0.00 & 0.00 & 0.00 & $\mathbf{1 . 0 0}$ & 0.00 & 0.00 & 0.00 & 0.00 & 0.00 \\
\hline
\end{tabular}


Table A5. Cont.

\begin{tabular}{cccccccccc}
\hline \multirow{2}{*}{ Objective } & \multicolumn{10}{c}{ Alternative $\boldsymbol{i}$} \\
\cline { 2 - 11 } & $\mathbf{1}$ & $\mathbf{2}$ & $\mathbf{3}$ & $\mathbf{4}$ & $\mathbf{5}$ & $\mathbf{6}$ & $\mathbf{7}$ & $\mathbf{8}$ & $\mathbf{9}$ \\
\hline $\mathrm{SC}$ & 0.06 & 2.08 & 2.00 & 1.30 & 1.68 & 0.00 & 0.18 & 0.00 & 0.70 \\
$\mathrm{PF}$ & 1 & 3 & 2 & 2 & 2 & 0 & 1 & 0 & 2 \\
$\mathrm{NPF}$ & 0.13 & 0.38 & 0.25 & 0.25 & 0.25 & 0.00 & 0.13 & 0.00 & 0.25 \\
$C_{E R M_{i k}}=\mathrm{SC} \times \mathrm{NPF}$ & 0.01 & 0.78 & 0.50 & 0.33 & 0.42 & 0.00 & 0.02 & 0.00 & 0.17 \\
Ranking & 7 & 1 & 2 & 4 & 3 & 8 & 6 & 9 & 5 \\
\hline
\end{tabular}

SC—-sum of all scores in each column, PF — participation factor, or how many times each alternative satisfies each objective, NPF-normalized participation factor, obtained as a ratio between the PF and total number of objectives; $C_{E R M_{i k}}$-criterion of the ranking; The most important criteria are in bold.

Table A6. Expected value for each variant, $E V_{i j}$.

\begin{tabular}{|c|c|c|c|c|c|c|c|c|c|c|c|}
\hline \multirow{2}{*}{ Alternative $i$} & \multicolumn{11}{|c|}{ Variant $j$} \\
\hline & 1 & 2 & 3 & 4 & 5 & 6 & 7 & 8 & 9 & 10 & 11 \\
\hline 1 & 0.005 & 0.001 & 0.003 & 0.003 & 0.001 & 0.004 & 0.002 & 0.004 & 0.004 & 0.003 & 0.004 \\
\hline 2 & 0.022 & 0.030 & 0.024 & 0.030 & 0.021 & 0.014 & 0.027 & 0.023 & 0.029 & 0.026 & 0.024 \\
\hline 3 & 0.033 & 0.039 & 0.034 & 0.041 & 0.023 & 0.018 & 0.031 & 0.027 & 0.034 & 0.025 & 0.024 \\
\hline 4 & 0.009 & 0.013 & 0.010 & 0.013 & 0.009 & 0.006 & 0.011 & 0.009 & 0.012 & 0.011 & 0.010 \\
\hline 5 & 0.029 & 0.027 & 0.028 & 0.031 & 0.017 & 0.018 & 0.024 & 0.025 & 0.029 & 0.023 & 0.024 \\
\hline 6 & 0.000 & 0.000 & 0.000 & 0.000 & 0.000 & 0.000 & 0.000 & 0.000 & 0.000 & 0.000 & 0.000 \\
\hline 7 & 0.002 & 0.001 & 0.002 & 0.002 & 0.001 & 0.002 & 0.001 & 0.002 & 0.002 & 0.002 & 0.002 \\
\hline 8 & 0.015 & 0.010 & 0.013 & 0.013 & 0.005 & 0.009 & 0.009 & 0.012 & 0.012 & 0.008 & 0.010 \\
\hline 9 & 0.017 & 0.016 & 0.016 & 0.018 & 0.009 & 0.010 & 0.013 & 0.014 & 0.016 & 0.012 & 0.012 \\
\hline \multirow{2}{*}{ Alternative $i$} & \multicolumn{11}{|c|}{ Variant $j$} \\
\hline & 12 & 13 & 14 & 15 & 16 & 17 & 18 & 19 & 20 & 21 & 22 \\
\hline 1 & 0.005 & 0.001 & 0.003 & 0.001 & 0.002 & 0.003 & 0.002 & 0.003 & 0.001 & 0.004 & 0.001 \\
\hline 2 & 0.020 & 0.017 & 0.010 & 0.024 & 0.021 & 0.013 & 0.015 & 0.012 & 0.022 & 0.011 & 0.021 \\
\hline 3 & 0.020 & 0.016 & 0.010 & 0.023 & 0.017 & 0.011 & 0.012 & 0.010 & 0.018 & 0.009 & 0.017 \\
\hline 4 & 0.008 & 0.007 & 0.004 & 0.010 & 0.009 & 0.005 & 0.006 & 0.005 & 0.009 & 0.004 & 0.009 \\
\hline 5 & 0.022 & 0.013 & 0.012 & 0.018 & 0.017 & 0.012 & 0.013 & 0.013 & 0.016 & 0.013 & 0.014 \\
\hline 6 & 0.000 & 0.000 & 0.000 & 0.000 & 0.000 & 0.000 & 0.000 & 0.000 & 0.000 & 0.000 & 0.000 \\
\hline 7 & 0.002 & 0.001 & 0.001 & 0.001 & 0.001 & 0.001 & 0.001 & 0.002 & 0.001 & 0.002 & 0.001 \\
\hline 8 & 0.010 & 0.004 & 0.006 & 0.004 & 0.005 & 0.005 & 0.004 & 0.006 & 0.004 & 0.007 & 0.003 \\
\hline 9 & 0.011 & 0.007 & 0.006 & 0.009 & 0.008 & 0.006 & 0.006 & 0.006 & 0.008 & 0.006 & 0.007 \\
\hline
\end{tabular}

\section{References}

1. Djordjević, B.; Krmac, E. Application of Multicriteria Decision-Making Methods in Railway Engineering: A Case Study of Train Control Information Systems (TCIS). In Modern Railway Engineering; IntechOpen: London, UK, 2018.

2. Mardani, A.; Zavadskas, E.K.; Khalifah, Z.; Jusoh, A.; Nor, K.M. Multiple Criteria Decision-Making Techniques in Transportation Systems: A Systematic Review of the State of the Art Literature. Transport 2015, 31, 359-385. [CrossRef]

3. Gerçek, H.; Karpak, B.; Kılınçaslan, T. A multiple criteria approach for the evaluation of the rail transit networks in Istanbul. Transportation 2004, 31, 203-228. [CrossRef]

4. Sivilevičius, H.; Maskeliūnaitè, L. The Criteria for Identifying the Quality of Passengers' Transportation by Railway and Their Ranking Using Ahp Method. Transport 2010, 25, 368-381. [CrossRef]

5. Maskeliūnaite, L.; Sivilevičius, H.; Podvezko, V. Research on the Quality of Passenger Transportation by Railway. Transport 2009, 24, 100-112. [CrossRef]

6. Sivileviãius, H.; Maskelinaite, L. The numerical example for evaluating the criteria describing the quality of the trip by international train. Econ. Manag. 2014, 7, 74-86. [CrossRef]

7. Dudek, M.; Solecka, K.; Richter, M. A multi-criteria appraisal of the selection of means of urban passenger transport using the Electre and AHP methods. Czas. Tech. 2018, 6, 79-93. [CrossRef]

8. Yücel, N.; Taşabat, S.E. The Selection of Railway System Projects with Multi Creteria Decision Making Methods: A Case Study for Istanbul. Procedia Comput. Sci. 2019, 158, 382-393. [CrossRef] 
9. Nassereddine, M.; Eskandari, H. An integrated MCDM approach to evaluate public transportation systems in Tehran. Transp. Res. Part A: Policy Pr. 2017, 106, 427-439. [CrossRef]

10. Wen, H.-Y.; Lin, S. Performance evaluation of highway passenger transport enterprises' operation based on the model of AHP-DEA. In Proceedings of the 2011 IEEE 18th International Conference on Industrial Engineering and Engineering Management, Changchun, China, 3-5 September 2011; Institute of Electrical and Electronics Engineers (IEEE): Piscataway, NJ, USA, 2011; pp. 811-815.

11. Hamurcu, M.; Eren, T. An Application of Multicriteria Decision-making for the Evaluation of Alternative Monorail Routes. Mathematics 2018, 7, 16. [CrossRef]

12. Ivić, M.; Marković, M.; Belošević, I.; Kosijer, M. Multicriteria decision-making in railway route planning and design. J. Croat. Assoc. Civ. Eng. 2012, 64, 195-205. [CrossRef]

13. Alpu, Özlem A methodology for evaluating satisfaction with high-speed train services: A case study in Turkey. Transp. Policy 2015, 44, 151-157. [CrossRef]

14. Qi, J.; Cacchiani, V.; Yang, L. Robust Train Timetabling and Stop Planning with Uncertain Passenger Demand. Electron. Notes Discret. Math. 2018, 69, 213-220. [CrossRef]

15. Stanković, M.; Gladović, P.; Popović, V. Determining the importance of the criteria of traffic accessibility using fuzzy AHP and rough AHP method. Decis. Making: Appl. Manag. Eng. 2019, 2, 86-104. [CrossRef]

16. Krmac, E.; Djordjević, B. Evaluation of the TCIS Influence on the capacity utilization using the TOPSIS method: Case studies of Serbian and Austrian railways. Oper. Res. Eng. Sci. Theory Appl. 2019, 2, 27-36. [CrossRef]

17. Liu, F.; Aiwu, G.; Lukovac, V.; Vukić, M. A multicriteria model for the selection of the transport service provider: A single valued neutrosophic DEMATEL multicriteria model. Decis. Making: Appl. Manag. Eng. 2018, 1, 121-130. [CrossRef]

18. Đorđević, D.; Stojic, G.; Stević, Ž.; Pamučar, D.; Vulevic, A.; Mišić, V. A New Model for Defining the Criteria of Service Quality in Rail Transport: The Full Consistency Method Based on a Rough Power Heronian Aggregator. Symmetry 2019, 11, 992. [CrossRef]

19. Zak, J.; Fierek, S.; Kruszyński, M. Evaluation of Different Transportation Solutions with the Application of Macro Simulation tools and Multiple Criteria Group Decision Making/Aiding Methodology. Procedia-Soc. Behav. Sci. 2014, 111, 340-349. [CrossRef]

20. D’Ovidio, F.D.; Leogrande, D.; Mancarella, R.; Schinzano, A.; Viola, D. A Multivariate Analysis of the Quality of Public Transport Services. Procedia Econ. Financ. 2014, 17, 238-247. [CrossRef]

21. Banaś, J.; Tomaszewska, K. Support in multi-criteria decision-making under uncertainty in a transport company. Oper. Res. Decis. 2013, 2, 11-23. [CrossRef]

22. Ngossaha, J.M.; Ngouna, R.H.; Archimède, B.; Nlong, J. Sustainability assessment of a transportation system under uncertainty: An integrated multicriteria approach. IFAC-PapersOnLine 2017, 50, 7481-7486. [CrossRef]

23. Isaai, M.T.; Kanani, A.; Tootoonchi, M.; Afzali, H.R. Intelligent timetable evaluation using fuzzy AHP. Expert Syst. Appl. 2011, 38, 3718-3723. [CrossRef]

24. Zhang, X.; Li, L.; Le Vine, S.; Liu, X. An integrated pricing/planning strategy to optimize passenger rail service with uncertain demand. J. Intell. Fuzzy Syst. 2019, 36, 435-448. [CrossRef]

25. Arsovski, S.; Todorovic, G.; Lazić, Z.; Arsovski, Z.; Ljepava, N.; Aleksic, A. Model for Selection of the Best Location Based on Fuzzy AHP and Hurwitz Methods. Math. Probl. Eng. 2017, 2017. [CrossRef]

26. Vesković, S.; Stević, Ž.; Karabašević, D.; Rajilić, S.; Milinković, S.; Stojić, G. A New Integrated Fuzzy Approach to Selecting the Best Solution for Business Balance of Passenger Rail Operator: Fuzzy PIPRECIA-Fuzzy EDAS Model. Symmetry 2020, 12, 743. [CrossRef]

27. Sekhar, C.R.; Minal; Madhu, E. Mode Choice Analysis Using Random Forrest Decision Trees. Transp. Res. Procedia 2016, 17, 644-652. [CrossRef]

28. Kaminski, B.; Jakubczyk, M.; Szufel, P. A framework for sensitivity analysis of decision trees. Cent. Eur. J. Oper. Res. 2017, 26, 135-159. [CrossRef]

29. Oral, L.O.; Tecim, V. Using Decision Trees for Estimating Mode Choice of Trips in Buca-Izmir. ISPRS Int. Arch. Photogramm. Remote. Sens. Spat. Inf. Sci. 2013, 139-145. [CrossRef]

30. Dorokhov, O.; Chernov, V. Application of the fuzzy decision trees for the tasks of alternative choices. Transp. Telecommun. 2011, 12, 4-11. 
31. Safitri, D.M.; Surjandari, I. Travel mode switching prediction using decision tree in Jakarta greater area. In Proceedings of the 2017 International Conference on Information Technology Systems and Innovation (ICITSI), Bandung, Indonesia, 23-24 October 2017; Institute of Electrical and Electronics Engineers (IEEE): Piscataway, NJ, USA, 2017; pp. 246-250.

32. Tsami, M.; Adamos, G.; Nathanail, E.; Budiloviča, E.B.; Jackiva, I.Y.; Magginas, V. A Decision Tree Approach for Achieving High Customer Satisfaction at Urban Interchanges. Transp. Telecommun. J. 2018, 19, 194-202. [CrossRef]

33. Ochiai, Y.; Masuma, Y.; Tomii, N. Improvement of timetable robustness by analysis of drivers' operation based on decision trees. J. Rail Transp. Plan. Manag. 2019, 9, 57-65. [CrossRef]

34. Saaty, T. Fundamentals of the Analytic network process-Dependence and feedback in decision-making with a single network. J. Syst. Sci. Syst. Eng. 2004, 13, 129-1577. [CrossRef]

35. Saaty, T. Fundamentals of Decision-Making and Priority Theory with the Analytic Hierarchy Process, 1st ed.; RWS: New York, NY, USA, 2000.

36. Munier, N. A new approach to the rank reversal phenomenon in MSDM with the SIMUS method. Mult. Criteria Decis. Mak. 2016, 11, 137-152. [CrossRef]

37. Munier, N. A Strategy for Using Multi-Criteria Analysis in Decision-Making; Springer: Berlin/Heidelberg, Germany, 2011.

38. Munier, N.; Hontoria, E.; Jiménez-Sáez, F. Strategic Approach in Multi-Criteria Decision Making. In International Series in Operations Research $\mathcal{E}$ Management Science; Springer International Publishing: Cham, Switzerland, 2019.

39. Taha, H.A. Operations Research: An Introduction, 9th ed.; University of Arkansas: Fayetteville, AR, USA, 2011.

40. Srivastava, T.N. Shailaja Rego. Statistics for Management; Tata McCraw-Hill Publishing Company: New York, NY, USA, 2008.

(C) 2020 by the author. Licensee MDPI, Basel, Switzerland. This article is an open access article distributed under the terms and conditions of the Creative Commons Attribution (CC BY) license (http://creativecommons.org/licenses/by/4.0/). 